\title{
A Multi-Criteria Decision Analysis to Include Environmental, Social, and Cultural Issues in the Sustainable Aggregate Production Plans
}

\author{
Seyyed Amir Babak Rasmi, Cem Kazan, Metin Türkay* \\ Department of Industrial Engineering, Koç University, Istanbul, Turkey, 34450
}

\begin{abstract}
Aggregate production planning (APP) that is an important concept of supply chain management $(\mathrm{SCM})$, is one of the tools to determine production rates, inventory levels, and workforce requirements for fulfilling customer demands in a multi-period setting. Traditional APP models employ a single objective function to optimize monetary issues only. In this paper, we present a multiobjective APP model to analyze economic, social, environmental, and cultural pillars inclusively; moreover, each pillar includes several sub-pillars in the model. The resulting model includes an accurate representation of the problem with binary and continuous variables under sustainability considerations. We illustrate the effectiveness of the model in an appliance manufacturer and solve the problem using an exact solution method for multi-objective mixed-integer linear programs (MOMILP). We find a large number of the non-dominated (ND) points in the objective function space and analyze their trade-offs systematically. We show how this framework supports multiple criteria decision making process in the APP problems in the presence of sustainability considerations. Our approach provides a comprehensive analysis of the ND points of sustainable APP (SAPP) problems, and hence, the trade-offs of objective functions are insightful to the decision makers.
\end{abstract}

Keywords: Supply Chain Management, Sustainability, Aggregate Planning, Multi-Criteria Decision Analysis, Multi-Objective Optimization, Mixed-Integer Linear Programming

\section{Introduction}

The impacts of high-speed industrialization attract the attention of many practitioners and researchers to sustainability. Depletion of large amounts of non-renewable resources and the role of cultural and social issues in SCM are crucial points that deserve more attention. Thus, leading companies have started to make decisions compatible with the sustainability considerations by significant investments (Chopra and Meindl, 2016). The concepts of SCM spread out through the entire organization; hence, sustainability can be tied to SCM and play a vital role for improving the decisions of supply chain managers. Then, sustainable SCM (SSCM) is an important enabler of significant improvements for the society in long-term. SSCM evolves supply chains, their individuals, and behaviors such that non-economic issues are respected (Hopkins et al., 2009; $\mathrm{PwC}$, 2013; Arslan, 2011).

Several factors increase the importance of sustainability. First, sustainability affects the company image; customers measure, compare, and rank the performance of these companies in sustainability. Then, sustainability adds value to the provided services or products, and hence, customers show tendency to these sustainable services/products (Hopkins et al., 2009; Melnyk et al., 2010; Bask et al., 2013). Conversely, customers do not prefer non-sustainable products. Customers may pay more for sustainable products (Trudel and Cotte, 2009). Second, sustainability considerations may be initiated as a response to some pressures from government regulations (Massaroni et al., 2015; Varsei, 2016). Third, natural resources depletion is a critical risk for the earth (Chopra

\footnotetext{
${ }^{*}$ Corresponding author

Email address: srasmi14@ku.edu.tr, ckazan14@ku.edu.tr, mturkay@ku.edu.tr (Seyyed Amir Babak Rasmi, Cem Kazan, Metin Türkay)
} 
and Meindl, 2016), and hence, to avoid dissolving a business, companies diversify their raw material/energy sources. Fourth, sustainability increases the performance of a company by being more appealing to the customers in competitive markets.

We observe that optimization and mathematical models deserve further discussion in terms of sustainability considerations since they are practically implementable for real-world problems (Davizón et al., 2015). The modification of traditional models by considering the requirements of sustainability is argued to be very important (Türkay, 2008; Benjaafar et al., 2013). On the other hand, multi-criteria decision making approaches are useful to consider economic, environmental, and social concerns which are termed as "Triple Bottom Line" (TBL), simultaneously (Elkington, 1998; Eskandarpour et al., 2015). Moreover, a decision maker may be interested in additional pillars not included in the TBL since three-dimensional models cannot completely characterize the bottom lines of sustainability (Cities and Governments, 2010). For example, the pillar of cultural concerns plays an essential role in sustainability and can be proposed as the fourth pillar (Yencken and Wilkinson, 2001; Soini et al., 2015; Astara, 2014).

We note that each pillar of sustainability has several sub-pillars. In terms of environmental aspects, energy and water consumption, using renewable energy sources, closed-loop supply chain, material selection, greenhouse gas (GHG) emission, etc. are mentioned in the literature. In terms of social aspects, working conditions, corporate social responsibility (CSR) projects, the effect of layoffs, working hours, training and education, child labor, diversity and equal opportunity, health and safety, etc. are discussed (Pfeffer, 2010; Massaroni et al., 2015; Varsei, 2016; Anvari and Turkay, 2017). However, the studies on SSCM, which intensely focus on both environmental pillar and social aspects of sustainability, attract relatively less interests (Salmona et al., 2010; Pfeffer, 2010; Brandenburg et al., 2014; Massaroni et al., 2015; Varsei, 2016).

SCM deals with several areas in a supply chain to improve material/information flow between the echelons; customer relationship management, procurement, manufacturing management, and product development are the cores of SCM. Manufacturing management is one of the main activities that is included in a supply chain and has a significant relationship with APP (Lackes, 2008; Towers and Ashford, 2001). When a supply chain manager needs to incorporate sustainability in SCM, focusing on manufacturing and planning are included in the most critical functions due to their strong effect on the pillars of sustainability. APP is the core activity in SCM that determines the amount of goods produced as well as planning the labor requirements. Therefore, we mainly focus on APP in this paper.

APP problems are represented through mathematical models which provide approximate solutions for macro planning at the firm level (Nahmias and Cheng, 2009). APP determines production rates, inventory levels, and workforce requirements of a production system to minimize the total costs - or maximize the total profit - while fulfilling customer demand in a certain period of time. Aggregation is vital for this planning since it is not possible to predict the timing and demand for individual items with any degree of accuracy. So, if an organization focuses on individual items, it will lose the flexibility to respond to the market (Stevenson et al., 2007). Then, an aggregate plan is provided for a representative product type. Note that disaggregation is required to translate an aggregate plan to more practical solutions and approaches at the lower decision levels of the firm (Nahmias and Cheng, 2009).

The main functionality of APP is to plan for tactical decisions where decisions in this level cover the next 2 to 18 months. However, a large number of issues can be included in APP, and hence, it can also appear as a powerful tool for considering strategic decisions which are closely connected with tactical decisions in the planning horizon. Then, APP programs enable to incorporate social and cultural aspects for establishments of an environment promoting sustainability. Therefore, a reformulation of an APP model meets the requirement of specific situations in practice and addresses economic criteria while discussing non-economic issues (Schroeder and Larson, 1986).

Eskandarpour et al. (2015) analyze 87 articles that consider mathematical models for supply chain networks. The study states that mixed-integer programs are the most used models and two third of the proposed models include more than one objective function. In some cases, multiple objective functions are used corresponding to the number of the pillars. The studies based on mathematical models adjust traditional models or present new mathematical models with sustainability considerations. The current literature mostly includes empirical studies rather than models and network designs based on the sustainability considerations (Salmona et al., 2010; Brandenburg 
et al., 2014). We summarize the most important and related studies that use mathematical modeling for the sustainability considerations in Table 1. This table shows that the developed supply chain mathematical models do not inclusively consider several concerns to address sustainability considerations.

Table 1: A summary of mathematical model-based studies

\begin{tabular}{|c|c|c|c|}
\hline Study & Env. & Soc. & Scope \\
\hline $\begin{array}{l}\text { Zhou et al. (2000); Chen and Andresen } \\
(2014) ; \text { Bhinge et al. (2015) }\end{array}$ & $\checkmark$ & $\checkmark$ & Supply chain optimization \\
\hline $\begin{array}{l}\text { Tsoulfas and Pappis (2008); Aviso et al. } \\
(2011)\end{array}$ & $\checkmark$ & $\times$ & Supply chain optimization \\
\hline Lu et al. (2007); Yamada et al. (2015) & $\checkmark$ & $\times$ & Supplier selection \\
\hline Azadnia et al. (2015) & $\checkmark$ & $\checkmark$ & Supplier selection and order allocation \\
\hline Türkay (2008) & $\checkmark$ & $\times$ & Energy production system design and operation \\
\hline $\begin{array}{l}\text { Dehghanian and Mansour (2009); } \\
\text { Harraz and Galal (2011) }\end{array}$ & $\checkmark$ & $\checkmark$ & Recovery network design \\
\hline Lee et al. (2010) & $\checkmark$ & $\times$ & Logistics network design \\
\hline Arslan and Turkay (2013) & $\checkmark$ & $\checkmark$ & Economic order quantity \\
\hline $\begin{array}{l}\text { Chen et al. (2013); Hovelaque and } \\
\text { Bironneau (2015) }\end{array}$ & $\checkmark$ & $\times$ & Economic order quantity \\
\hline Pérez-Fortes et al. (2012) & $\checkmark$ & $\checkmark$ & Biomass energy system design and operation \\
\hline Benjaafar et al. (2013) & $\checkmark$ & $\times$ & Lot-sizing \\
\hline Santibañez-Aguilar et al. (2014) & $\checkmark$ & $\checkmark$ & $\begin{array}{l}\text { Biorefinery site selection and operations } \\
\text { planning }\end{array}$ \\
\hline Validi et al. (2014) & $\checkmark$ & $\times$ & Capacitated distribution network design \\
\hline Fareeduddin et al. (2015) & $\checkmark$ & $\times$ & Closed-loop supply chain network design \\
\hline Soleimani et al. (2017) & $\checkmark$ & $\checkmark$ & Closed-loop supply chain network design \\
\hline Garbie (2015) & $\checkmark$ & $\checkmark$ & Manufacturing enterprises \\
\hline Schenker et al. (2015) & $\checkmark$ & $\times$ & Manufacturing planning \\
\hline $\begin{array}{l}\text { Türkay et al. (2016); Hahn and } \\
\text { Brandenburg (2017) }\end{array}$ & $\checkmark$ & $\checkmark$ & Aggregate production planning \\
\hline Anvari and Turkay (2017) & $\checkmark$ & $\checkmark$ & Hub location for food supply chain \\
\hline Musavi and Bozorgi-Amiri (2017) & $\checkmark$ & $\checkmark$ & Facility location \\
\hline
\end{tabular}

In this paper, we aim to combine the concepts of APP with a number of sustainability considerations and propose a framework that supports the analysis of multiple criteria in decision making process. In terms of mathematical modeling, we present a SAPP model by the incorporation of the cultural vitality and placing a significant emphasis on social issues which are not sufficiently addressed in the literature. Our SAPP model is a MILP that includes both binary and continuous decision variables. Note that binary variables represent strategic or more important tactical decisions in many cases. One of the recent studies that redesign the APP model with economic viability, environmental responsibility, and social equity is proposed by Türkay et al. (2016). They reveal gaps in the current literature in terms of combining the economic, environmental, and social pillars within the APP models. Applying multi-criteria approaches for SAPP in chemical industries is also proposed while sustainability considerations are addressed by profit, overtime, and carbon emission as the sub-pillars of TBL (Hahn and Brandenburg, 2017). In this regard, we enrich the model by including several sub-pillars for the economic, environmental, social, and cultural pillars of sustainability.

The sustainability considerations in SCM and APP lead to a multi-criteria decision making problem, and hence, it is necessary to analyze the effect of these often-conflicting criteria systematically. In terms of the solution method and analysis of the framework, we find a large subset of the ND points such that each of them corresponds to a different binary solution or strategic decision. Therefore, we obtain a large number of strategic decisions that result in ND points or efficient solutions and are not considered in the cost-oriented solution approach. We also comprehensively analyze the trade-offs of four objective functions and solutions. We show the effectiveness of the framework on a household appliance manufacturer. We show that our multiple criteria decision analysis approach supports the decision making process in the SAPP problems and provides insightful ideas for decision makers in an industrial case study.

This paper is organized as follows. We define our problem, state the constraints and the terms of objective functions, and establish a link between the constraints/objective functions and sustainability in Section 2. Then, we establish our quad-objective programming model to address sustainability considerations in an APP problem in Section 3. In Section 4, we briefly describe our solution method for solving the quad-objective APP model and use it for an industrial case study. Next, we discuss the results to show a few managerial insights. Finally, we show our conclusions 
and contributions in Section 5 .

\section{Problem Definition}

Traditional APP models are cost-oriented; however, the widespread adoption of economic factors while ignoring environmental, social, and cultural issues in a supply chain is a flawed approach. The economic, environmental, social, and cultural issues build the pillars of an organization altogether. We aim to address sustainability considerations in a supply chain by building a multiobjective approach in APP. We remodel the traditional APP model and present a groundbreaking APP model with four objective functions and some constraints to assign equal importance to the economic, environmental, social, and cultural pillars.

Figure 1 shows our approach for each pillar of sustainability. For economic issues, we discuss the costs and aim to maximize profit. Then, in the environmental pillar, we address reducing GHG emission, non-renewable energy use, and integration of a renewable energy source into the system as sub-pillars. In terms of the social pillar, we focus on employee safety improvement, reducing work-family conflicts, employee gender equity, customer satisfaction level, and implementing CSR projects. In the pillar of cultural vitality, we discuss employee well-being and performing innovative projects for enriching the cultural environment towards environmental/social stewardship and inclusiveness. We consider these four pillars and sub-pillars in the objective functions and constraints.

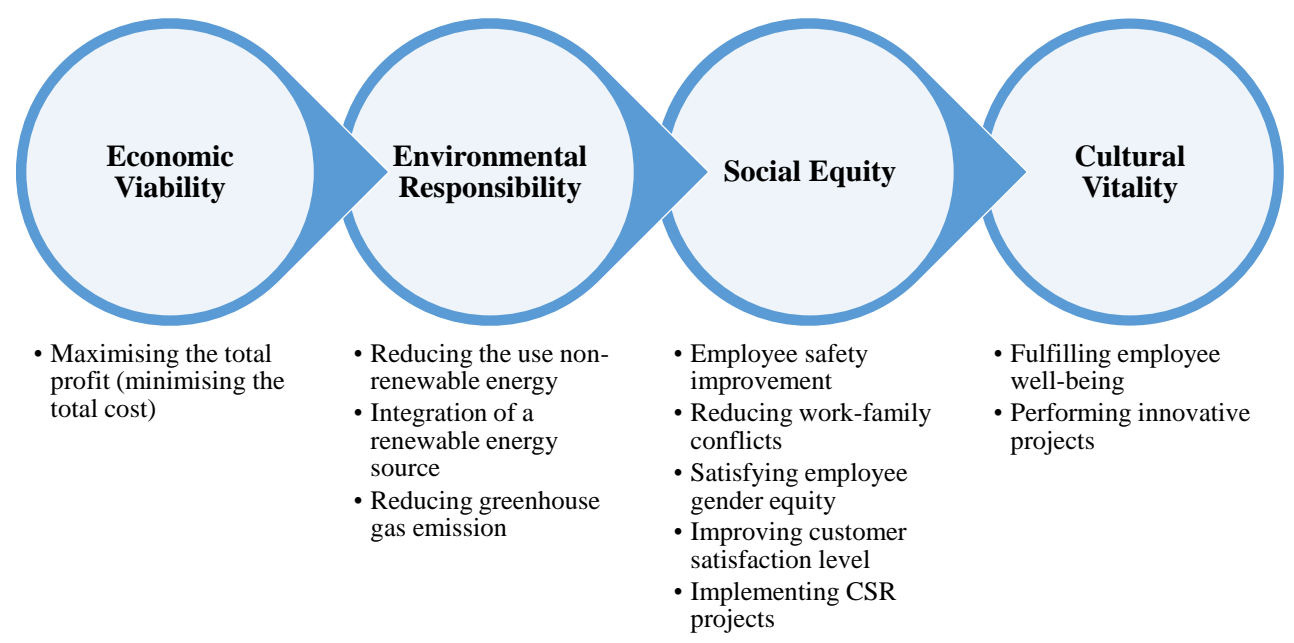

Figure 1: The pillars and sub-pillars addressed in the SAPP model

In the traditional APP models, the following costs are considered: raw material, cost of regular and overtime working hours, cost of hiring and firing workers, inventory holding cost, stock-out cost, and subcontracting cost (Chopra and Meindl, 2016; Nahmias and Cheng, 2009; Stevenson et al., 2007; Russell and Taylor-Iii, 2008). We keep these costs and add the following monetary issues to our model.

- tax of carbon dioxide emission (calculated for the emission generated by production, inventory holding, and subcontract activities),

- electricity cost (calculated for the consumed electricity in production, inventory holding, and subcontract activities),

- cost of integration of a renewable energy source into the system (amortized cost with respect to the new energy source),

- cost of implementing CSR projects, and

- cost of substituting old technologies with new innovative technologies (amortized cost with respect to the innovative projects). 
In order to address several sub-pillars in environmental, social, and cultural issues, we use different indicators. These indicators are shown in Table 2. Moreover, we show that either the indicators are used within constraints, or objective functions, or both. When an indicator is used in the constraints, a formulation of the indicator — for example the sum of the indicator over the planning horizon - is either restricted or considered for formulating a number of constraints. When an indicator is used within the objective functions, a formulation of that is either minimized/maximized or used to formulate other sub-pillars.

Table 2: Pillars, sub-pillars, and their indicators in SAPP

\begin{tabular}{|c|c|c|c|c|}
\hline pillar & sub-pillar & indicator & $\begin{array}{l}\text { obj. } \\
\text { func. }\end{array}$ & $\begin{array}{l}\text { con- } \\
\text { straint }\end{array}$ \\
\hline \multirow[t]{3}{*}{$\begin{array}{l}\text { environ- } \\
\text { ment }\end{array}$} & GHG emission & $\begin{array}{l}\text { amount of GHG emission because of } \\
\text { different activities }\end{array}$ & $\checkmark$ & $\checkmark$ \\
\hline & $\begin{array}{l}\text { consumed non-renewable } \\
\text { energy }\end{array}$ & $\begin{array}{l}\text { consumed electricity generated from } \\
\text { non-renewable sources }\end{array}$ & $\checkmark$ & $\checkmark$ \\
\hline & & integration of a renewable energy source & $\checkmark$ & $\checkmark$ \\
\hline \multirow[t]{7}{*}{ society } & employee safety & overtime working hours & $\checkmark$ & $\checkmark$ \\
\hline & & training newly hired workers & $\times$ & $\checkmark$ \\
\hline & work-family conflicts & overtime working hours & $\checkmark$ & $\checkmark$ \\
\hline & employee gender equity & number of female workers & $\checkmark$ & $\checkmark$ \\
\hline & & $\begin{array}{l}\text { minimum proportion of the employees of a } \\
\text { gender }\end{array}$ & $\times$ & $\checkmark$ \\
\hline & Customer satisfaction level & number of stock-outs & $\checkmark$ & $\checkmark$ \\
\hline & CSR projects & number of implemented CSR projects & $\checkmark$ & $\checkmark$ \\
\hline \multirow[t]{2}{*}{ culture } & employee well-being & number of layoffs & $\checkmark$ & $\checkmark$ \\
\hline & innovative projects & number of perfromed innovative projects & $\checkmark$ & $\checkmark$ \\
\hline
\end{tabular}

In Table 3, for each indicator, we report a number of issues which make the indicator important. In other words, the existence of these issues makes using the mentioned indicators reasonable. These issues motivate practitioners and researchers to control the indicators for establishing sustainable supply chains.

Regarding the environmental pillar, we assume that manufacturing, inventory holding, and subcontracting activities are the main activities where energy is used. Moreover, the emitted GHG or carbon dioxide is originated from these activities.

Table 3: Important indicators and their significance

\begin{tabular}{|c|c|}
\hline indicator & related issues, significance, and motivations \\
\hline $\begin{array}{l}\text { amount of GHG emission and consumed } \\
\text { electricity generated from non-renewable } \\
\text { sources } \\
\text { integration of a renewable energy source }\end{array}$ & $\begin{array}{l}\text { air/water pollution, overusing non-renewable energy sources, } \\
\text { overusing raw materials, damaging ecosystems, biodiversity } \\
\text { loss, deforestation, increasing global average temperature } \\
\text { (Handfield et al., 2005; Türkay, 2008; Aviso et al., 2011; } \\
\text { Bhinge et al., 2015; Anvari and Turkay, 2017) } \\
\text { independency from non-renewable energy sources }\end{array}$ \\
\hline $\begin{array}{l}\text { overtime working hours/ training newly } \\
\text { hired workers }\end{array}$ & $\begin{array}{l}\text { health, safety, and living condition of individuals, } \\
\text { communities, customers, and stakeholders (Dyllick and } \\
\text { Hockerts, 2002; Bhinge et al., 2015), a larger number of } \\
\text { workplace accidents when overtime increases and training } \\
\text { programs are not held (Türkay et al., 2016; May et al., 2015; } \\
\text { Hrymak and Perezgonzalez, 2007; Bibowei, 2015; Wagstaff } \\
\text { and Lie, 2011) }\end{array}$ \\
\hline $\begin{array}{l}\text { number of female workers/ minimum } \\
\text { proportion of the employees of a gender }\end{array}$ & $\begin{array}{l}\text { equal job opportunities regardless of ethnicity, gender, age, } \\
\text { religion, disability, nationality, and sexuality (CAAWS, } \\
2017 \text { ), a powerful economy when percentage of female } \\
\text { employees is high (Bhinge et al., 2015; European Parliament, } \\
\text { 2016) }\end{array}$ \\
\hline number of stock-outs & $\begin{array}{l}\text { the right product in the right place at the right time (ECR, } \\
2017 \text { ) }\end{array}$ \\
\hline number of implemented CSR projects & $\begin{array}{l}\text { voluntarily CSR projects add value to the society and } \\
\text { improve financial performance, company image improvement } \\
\text { (Sarkis et al., 2010; Zimara and Eidam, 2015) }\end{array}$ \\
\hline number of layoffs & $\begin{array}{l}\text { physical and mental problems for a worker who got fired, } \\
\text { tendency to violence and suicide increase with a layoff } \\
\text { (Hawkes, 2001) }\end{array}$ \\
\hline number of perfromed innovative projects & $\begin{array}{l}\text { creativity, and innovation (Hawkes, 2001), low price, } \\
\text { responsiveness, and high quality attract people to a product } \\
\text { or a job (Melnyk et al., 2010), innovative systems are more } \\
\text { environment-friendly, longer holidays and compensations } \\
\text { when production capacity is larger }\end{array}$ \\
\hline
\end{tabular}

Organizations take social and ethical roles to solve the problems of society by CSR projects. Therefore, we consider that the implementation of CSR projects increases the social performance 
and positively affects the customer demand. When companies invest on CSR projects, they also require to advertise and announce their contributions to the society. Regarding the type of project, when a project is implemented for one period, after a number of periods, the society positively reacts to the social contributions and is attracted to the products of these companies. The market's positive reaction to the project lasts for a number of periods. We assume that it lasts for one month.

Cultural heritage is an important and unique asset to humanity that cannot be replaced or renewed. Culture addresses creativity, knowledge, and diversity in sustainable development (Cities and Governments, 2010). Moreover, an intellectual wealth of any group is part of their culture and requires improvement. Although cultural issues can be interpreted as a part of the social pillar of sustainability, we separate culture as the fourth pillar to place more emphasis on it. We assume that while performing an innovative project in a period decreases the production capacity of that period, it improves the production capacity in the subsequent periods. Note that we call a project innovative if it results in a larger production capacity while less energy and less GHG is emitted. The lag between performing an innovative project and the affecting time varies from one to multiple periods. We assume that the size of the performed innovative projects is such that we can see the positive effects one period after the implementation. Then, an organization takes the advantages of the performed projects until the end of planning horizon.

In general, when an organization commits to CSR and innovative projects as a strategic priority, the individual projects can be implemented within several months and the results for some of these projects appear in one or a few months (e.g. energy efficiency improvement or changing the equipments in the assembly lines to accommodate female or disabled workers). Therefore, the effects of such innovative and CSR projects can be observed in short/medium-term which are within the scope of SAPP.

\section{SAPP Model}

A number of basic mathematical models and assumptions for APP problems are presented in the literature (Chopra and Meindl, 2016; Nahmias and Cheng, 2009; Stevenson et al., 2007; Russell and Taylor-Iii, 2008). We provide a mathematical programming model for APP problems with sustainability considerations that are discussed in Section 2. We establish the SAPP model with four objective functions using continuous and discrete decision variables. We address economic, environmental, social, and cultural concerns by several terms and indicators as discussed in Section 2 and Table 2. In Table 4, we define sets and parameters, and decision variables are defined in Table 5 .

Let $z_{\text {eco }}$ given in (1) be the objective function associated with the economic pillar to maximize the total profit.

$$
\begin{aligned}
\max z_{\text {eco }}= & \\
& \sum_{t \in T} s p \times S_{t} \\
& -\sum_{t \in T} c_{L} \times h \times n_{t} \times\left(M W_{t}+F W_{t}\right) \\
& -\sum_{t \in T}\left(c_{H} \times\left(M H_{t}+F H_{t}\right)+c_{F} \times\left(M F_{t}+F F_{t}\right)\right) \\
& -\sum_{t \in T} c_{O} \times O_{t} \\
& -\sum_{t \in T} c_{M} \times P_{t} \\
& -\sum_{t \in T} c_{I} \times I_{t} \\
& -\sum_{t \in T} c_{S U} \times S U_{t}
\end{aligned}
$$




$$
\begin{aligned}
& -\sum_{t \in T} c_{S O} \times S O_{t} \\
& -\sum_{t \in T} c_{E} \times\left(e_{I} \times I_{t}+e_{P} \times P_{t}+e_{S U} \times S U_{t}-e_{t}^{R E} \times X_{t}^{R E}\right) \\
& -\sum_{t \in T} c_{C T} \times\left(g_{I} \times I_{t}+g_{P} \times P_{t}+g_{S U} \times S U_{t}\right) \\
& -\sum_{t \in T} c_{t}^{R E} \times X_{t}^{R E} \\
& -\sum_{t \in T} \sum_{j \in J} c_{t j}^{C S R} \times C S R_{t j} \\
& -\sum_{t \in T} \sum_{k \in K} c_{t k}^{I N} \times Y_{t k},
\end{aligned}
$$

where Eq (1a) is the revenue of selling products. (1b), (1c), and (1d) are the salary of employees, hiring/firing costs, and overtime costs, respectively. Material, inventory holding, subcontracting, and stock-out costs are presented in (1e), (1f), (1g), and (1h), respectively. Eq (1i) includes energy cost of inventory holding, manufacturing, and subcontracting activities with the saving originated from integrating a renewable energy source into the system. We assume that when a manufacturer integrates a renewable energy source into the system at period $t$, he spends $c_{t}^{R E} \$$ for the integration. Then, he uses the supplied energy $\left(e_{t}^{R E}\right)$ for the rest of the planning horizon. Hence, we consider this issue as shown in (1i). ( $1 \mathrm{j}$ ) displays the tax of carbon dioxide emission because of inventory holding, manufacturing, and subcontracting activities. Equations (1k) and (11) incorporate the cost of integrating a renewable energy source and the implementation of CSR projects, respectively. Eq $(1 \mathrm{~m})$ demonstrates the net cost of performing innovative projects such that savings from the tax of reduced energy usage and GHG emission - as the results of innovation projects - are calculated within the net cost.

For the environmental pillar, let $z_{\text {env }}$ given in (2) be the objective function that shows environmental issues.

$$
\begin{aligned}
\min z_{\text {env }}= & \\
& \operatorname{coef} f_{\text {env } 1}\left(\sum_{t \in T}\left(g_{I} \times I_{t}+g_{P} \times P_{t}+g_{S U} \times S U_{t}\right)\right. \\
& \left.-\sum_{t \in T} \sum_{k \in K}\left(g_{t k}^{-} \times Y_{t k}\right)\right) \\
& +\operatorname{coe}_{\text {env } 2}\left(\sum_{t \in T}\left(e_{I} \times I_{t}+e_{P} \times P_{t}+e_{S U} \times S U_{t}\right)\right. \\
& \left.-\sum_{t \in T}\left(e_{t}^{R E} \times X_{t}^{R E}\right)-\sum_{t \in T} \sum_{k \in K}\left(e_{t k}^{-} \times Y_{t k}\right)\right),
\end{aligned}
$$

where (2a) is the total GHG emission multiplied by coefenv1 and $(2 \mathrm{~b})$ is the total consumed non-renewable energy multiplied by coef $f_{\text {env2 }}\left(c o e f_{\text {env1 } 1}\right.$ and coef $f_{\text {env2 }}$ are used due to the unit and scale difference of the sub-pillars, and discussed in Section 4.2). Note that performing innovative projects decreases GHG emission and energy consumption (see terms $-\sum_{t \in T} \sum_{k \in K}\left(g_{t k}^{-} \times Y_{t k}\right)$ and $-\sum_{t \in T} \sum_{k \in K}\left(e_{t k}^{-} \times Y_{t k}\right)$ in (2a) and (2b), respectively). Moreover, integrating a renewable energy source into the system decreases the consumed energy generated by non-renewable sources as of $\sum_{t \in T}\left(e_{t}^{R E} \times X_{t}^{R E}\right)$.

$z_{s o c}$ given in (3) is the objective function for the social pillar.

$$
\begin{aligned}
\min z_{\text {soc }}= & \\
& \operatorname{coef} f_{\text {soc } 1}\left(\sum_{t \in T} O_{t}\right) \\
& +\operatorname{coef} f_{s o c 2}\left(\sum_{t \in T}\left(M W_{t}-F W_{t}\right)\right)
\end{aligned}
$$


Table 4: The sets and parameters of the SAPP

\begin{tabular}{|c|c|c|c|}
\hline $\begin{array}{l}T \\
K\end{array}$ & $\begin{array}{l}\text { The set of periods in the planning horizon and } \\
t=1, \ldots,|T| \\
\text { The set of innovative projects and } k=1, \ldots,|K| \text {. }\end{array}$ & $J$ & The set of CSR projects and $j=1, \ldots,|J|$. \\
\hline$s p$ & Selling price of a product $(\$ /$ item $)$ & $c_{L}$ & Salary of one worker per hour $(\$ /($ worker $\times$ hour $))$ \\
\hline$c_{H}$ & Cost of hiring a new worker ( $\$ /$ worker) & $c_{F}$ & Cost of firing a worker ( $\$ /$ worker) \\
\hline$c_{M}$ & Material cost per product $(\$ /$ item $)$ & $c_{O}$ & Overtime cost per hour per worker $(\$ /($ worker $\times$ hour $))$ \\
\hline$c_{I}$ & $\begin{array}{l}\text { Holding cost per product in one period } \\
(\$ /(\text { item } \times \text { period }))\end{array}$ & $c_{S U}$ & Subcontracting cost per product $(\$ /$ item $)$ \\
\hline$c_{S O}$ & Stock-out cost per product (\$/item) & $c_{C T}$ & $\begin{array}{l}\text { Carbon dioxide tax per tonne of carbon dioxide emission } \\
(\$ / \text { tonne })\end{array}$ \\
\hline$c_{E}$ & Electricity cost per unit of energy $(\$ / \mathrm{kWh})$ & $c_{t}^{R E}$ & $\begin{array}{l}\text { Integration cost of a renewable energy source into the } \\
\text { system in period } t(\$)\end{array}$ \\
\hline$c_{t j}^{C S R}$ & Implementation cost of CSR project $j$ in period $t(\$)$ & $c_{t k}^{I N}$ & $\begin{array}{l}\text { The net cost of performing innovative project } k \text { in } \\
\text { period } t(\$)\end{array}$ \\
\hline$g_{I}$ & $\begin{array}{l}\text { GHG emission per product held in the inventory in a } \\
\text { period (tonne } /(\text { item } \times \text { period }))\end{array}$ & $g_{P}$ & GHG emission for manufacturing a product (tonne/item) \\
\hline$g_{S U}$ & $\begin{array}{l}\text { GHG emission per product which is subcontracted } \\
\text { (tonne/item) }\end{array}$ & $e_{I}$ & $\begin{array}{l}\text { Electricity used per product held in the inventory in a } \\
\text { period }(\mathrm{kWh} /(\text { item } \times \text { period }))\end{array}$ \\
\hline$e_{P}$ & $\begin{array}{l}\text { Electricity used for manufacturing a product } \\
(\mathrm{kWh} / \text { item })\end{array}$ & $e_{S U}$ & Electricity used per subcontracted product (kWh/item) \\
\hline$e_{t}^{R E}$ & $\begin{array}{l}\text { Generated energy by integrating a renewable energy } \\
\text { source if it is integrated in period } t(\mathrm{kWh})\end{array}$ & $g_{t k}^{-}$ & $\begin{array}{l}\text { Average reduction in GHG emission during the } \\
\text { remaining part of the planning horizon if innovative } \\
\text { project } k \text { is performed in period } t \text { (tonne) }\end{array}$ \\
\hline$e_{t k}^{-}$ & $\begin{array}{l}\text { Average reduction in the consumed electricity during the } \\
\text { remaining part of the planning horizon if innovative } \\
\text { project } k \text { is performed in period } t(\mathrm{kWh})\end{array}$ & $\xi_{g}$ & $\begin{array}{l}\text { Permitted maximum of GHG emission during the } \\
\text { planning horizon (tonne) }\end{array}$ \\
\hline$\xi_{e}$ & $\begin{array}{l}\text { Permitted maximum consumed electricity from } \\
\text { non-renewable sources during the planning horizon } \\
(\mathrm{kWh})\end{array}$ & $l_{\text {Lim }}$ & $\begin{array}{l}\text { Permitted maximum percentage of layoffs in a period } \\
(\%)\end{array}$ \\
\hline$o_{L i m}$ & Overtime limit per worker in a period (hour/period) & $\operatorname{csr}_{L i}$ & $\begin{array}{l}\text { Minimum number of implemented CSR projects during } \\
\text { the planning horizon (\# of projects) }\end{array}$ \\
\hline$i n_{L i m}$ & $\begin{array}{l}\text { Minimum number of performed innovative projects } \\
\text { during the planning horizon (\# of projects) }\end{array}$ & & $\begin{array}{l}\text { Maximum number of subcontracted products in a period } \\
\text { (item/period) }\end{array}$ \\
\hline $\mathrm{fm}$ & Minimum proportion of the employees of a gender (\%) & $\alpha$ & Customer satisfaction level (\%) \\
\hline$d_{t}$ & Demand in period $t$ (item) & $d_{t j}^{+}$ & implemented such that it shows its impact in period $t$ \\
\hline$h$ & Regular-time working hours per day (hour/day) & $n_{t}$ & Number of working days in period $t$ (day) \\
\hline$p_{M}$ & $\begin{array}{l}\text { in a day by one experienced male worker } \\
(\text { item }(\text { worker } \times \text { day }))\end{array}$ & $p h$ & Average productivity rate of a newly hired worker (\%) \\
\hline$p f$ & Average productivity rate of a female worker (\%) & $c a_{t k}^{-}$ & $\begin{array}{l}\text { Capacity decrease in period } t \text { because of performing } \\
\text { innovative project } k \text { in period } t \text { (item) }\end{array}$ \\
\hline$c a_{t k}^{+}$ & $\begin{array}{l}\text { Capacity increase in period } t \text { thanks to performing } \\
\text { innovative project } k \text { in one of previous periods (item) }\end{array}$ & $M W_{0}$ & Initial male workforce level (worker) \\
\hline$F W_{0}$ & Initial female workforce level (worker) & $I_{0}$ & Initial inventory level (item) \\
\hline
\end{tabular}

Table 5: The decision variables of the SAPP

\begin{tabular}{|c|c|c|c|}
\hline$P_{t}$ & \# of manufactured products in period $t$ (item) & $O_{t}$ & $\begin{array}{l}\text { Overtime working hours in period } t \\
((\text { worker } \times \text { hour }) / \text { period })\end{array}$ \\
\hline$I_{t}$ & \# of products in warehouse at the end of period $t$ (item) & $S_{t}$ & $\#$ of sold products in period $t$ (item) \\
\hline$S U_{t}$ & \# of subcontracted products in period $t$ (item) & $S O_{t}$ & \# of stock-outs in period $t$ (item) \\
\hline$F W_{t}$ & \# of female workers in period $t$ (worker) & $M W_{t}$ & \# of male workers in period $t$ (worker) \\
\hline$F H_{t}$ & $\begin{array}{l}\text { \# of hired female workers at the beginning of period } t \\
\text { (worker) }\end{array}$ & $M H_{t}$ & $\begin{array}{l}\text { \# of hired male workers at the beginning of period } t \\
\text { (worker) }\end{array}$ \\
\hline$F F_{t}$ & $\begin{array}{l}\# \text { of fired female workers at the beginning of period } t \\
\text { (worker) }\end{array}$ & $M F_{t}$ & $\begin{array}{l}\text { \# of fired male workers at the beginning of period } t \\
\text { (worker) }\end{array}$ \\
\hline$X_{t}^{R E}$ & $\begin{array}{l}1 \text { if renewable energy source is integrated in period } t, 0 \\
\text { otherwise }\end{array}$ & $C S R_{t j}$ & $\begin{array}{l}1 \text { if CSR project } j \text { is implemented and shows its impact } \\
\text { in period } t, 0 \text { otherwise }\end{array}$ \\
\hline$Y_{t k}$ & $\begin{array}{l}1 \text { if innovative project } k \text { is performed in period } t, 0 \\
\text { otherwise }\end{array}$ & $Y_{t k}^{A}$ & $\begin{array}{l}1 \text { if innovative project } k \text { has already been performed in a } \\
\text { period before } t, 0 \text { otherwise }\end{array}$ \\
\hline
\end{tabular}

$$
\begin{aligned}
& +\operatorname{coe} f_{\text {soc } 3}\left(\sum_{t \in T} S O_{t}\right) \\
& -\operatorname{coef} f_{\text {soc } 4}\left(\sum_{t \in T} \sum_{j \in J} C S R_{t j}\right)
\end{aligned}
$$

where (3a) minimizes the overtime working hours to improve the safety of employees and reduces work-family conflicts. Regarding the employee gender equity, we assume that $\mathrm{fm}$ - and consequently the constraints given in $(5 \mathrm{~d})$ and $(5 \mathrm{e})$ - avoids having a large difference between male 
and female workers. Therefore, we use (3b) to assign more priority to hiring female workers. (3c) minimizes the total stock-outs to improve customer satisfaction level. Moreover, we use (3d) to maximize the number of implemented CSR projects.

$z_{c u l}$ given in (4) is the objective function that models the cultural pillar in the system.

$$
\begin{aligned}
\max z_{c u l}= & \\
& -\operatorname{coef}_{\text {cul } 1}\left(\sum_{t \in T}\left(M F_{t}+F F_{t}\right)\right) \\
& +\operatorname{coef}_{\text {cul } 2}\left(\sum_{t \in T} \sum_{k \in K} Y_{t k}^{A}\right),
\end{aligned}
$$

where (4a) minimizes the number of layoffs during the planning horizon to improve employee wellbeing. (4b) maximizes the number of performed innovative projects. Moreover, note that (4b) gives preference to performing innovative projects in the earlier periods of the planning horizon in order to have the increased capacity available at later periods.

Next, we formulate the constraints of the SAPP model. These constraints are constructed based on the sustainability considerations that is discussed in Section 2. Constraints given in (5) refer to the constraints that conduct directly the sustainability considerations. Furthermore, constraints given in (6) refer to the constraints of the traditional APP problem and identify the type of decision variables.

$$
\begin{aligned}
& \sum_{t \in T}\left(g_{I} \times I_{t}+g_{P} \times P_{t}+g_{S U} \times S U_{t}\right)-\sum_{t \in T} \sum_{k \in K}\left(g_{t k}^{-} \times Y_{t k}\right) \leq \xi_{g}, \\
& \sum_{t \in T}\left(e_{I} \times I_{t}+e_{P} \times P_{t}+e_{S U} \times S U_{t}-e_{t}^{R E} \times X_{t}^{R E}\right) \\
& -\sum_{t \in T} \sum_{k \in K}\left(e_{t k}^{-} \times Y_{t k}\right) \leq \xi_{e}, \\
& O_{t} \leq o_{\text {Lim }} \times\left(M W_{t}+F W_{t}\right), \forall t \in T, \\
& f m \times\left(M W_{t}+F W_{t}\right) \leq F W_{t}, \forall t \in T, \\
& f m \times\left(M W_{t}+F W_{t}\right) \leq M W_{t}, \forall t \in T, \\
& S_{t} \geq \alpha \times d_{t} \times\left(1+\sum_{j \in J} d_{t j}^{+} \times C S R_{t j}\right), \forall t \in T, \\
& \sum_{t \in T} \sum_{j \in J} C S R_{t j} \geq \operatorname{csr}_{\text {Lim }}, \sum_{t \in T} \sum_{k \in K} Y_{t k} \geq i n_{\text {Lim }}, \\
& l_{L i m} \times\left(F W_{t-1}+M W_{t-1}\right) \geq F F_{t}+M F_{t}, \forall t \in T \text {, } \\
& Y_{1 k}^{A}=0, \forall k \in K, \quad Y_{t k}^{A}=\sum_{t^{\prime} \in\{1,2, . ., t-1\}} Y_{t^{\prime} k}, \forall k \in K, \forall t \in T \backslash\{1\}, \\
& \sum_{t \in T} Y_{t k} \leq 1, \forall k \in K, \quad \sum_{t \in T} X_{t}^{R E} \leq 1, \forall t \in T \\
& M W_{t}=M W_{t-1}+M H_{t}-M F_{t}, F W_{t}=F W_{t-1}+F H_{t}-F F_{t}, \forall t \in T, \\
& I_{t}=I_{t-1}+P_{t}+S U_{t}-S_{t}, \forall t \in T \text {, } \\
& S_{t}+S O_{t}=d_{t} \times\left(1+\sum_{j \in J} d_{t j}^{+} \times C S R_{t j}\right), \forall t \in T, \\
& P_{t} \leq p_{M} \times n_{t} \times\left(M W_{t}+F W_{t} \times p f-(1-p h) \times M H_{t}\right. \\
& \left.-(p f-p h) \times F H_{t}\right)+\frac{p_{M}}{h} \times O_{t}+\sum_{k \in K}\left(c a_{t k}^{+} \times Y_{t k}^{A}-c a_{t k}^{-} \times Y_{t k}\right), \forall t \in T, \\
& S U_{t} \leq s u_{\text {Lim }}, \forall t \in T
\end{aligned}
$$




$$
\begin{aligned}
& F W_{t}, M W_{t}, F H_{t}, M H_{t}, F F_{t}, M F_{t} \in \mathbb{Z}^{+} \cup\{0\}, \forall t \in T, \\
& P_{t}, I_{t}, S_{t}, S U_{t}, S O_{t} \in \mathbb{Z}^{+} \cup\{0\}, \forall t \in T, \\
& O_{t} \geq 0, \forall t \in T, \quad X_{t}^{R E} \in\{0,1\}, \forall t \in T, C S R_{t j} \in\{0,1\}, \forall j \in J, \forall t \in T, \\
& Y_{t k}, Y_{t k}^{A} \in\{0,1\}, \forall k \in K, \forall t \in T,
\end{aligned}
$$

where (5a) restricts the total GHG emission. We also consider the positive effect of performing innovative projects on GHG emission. (5b) restricts the consumed non-renewable energy based on electricity. In this constraint, we also consider the effect of integrating a renewable energy source and performing innovative projects. (5c) restricts overtime working hours per worker in each period. (5d) and (5e) satisfy employee gender equity in each period. (5f) prepares a lower bound for customer satisfaction level in each period. Note that we also consider demand change due to the implementation of CSR projects. (5g) forces our model to implement a minimum number of CSR and innovative projects during the planning horizon. (5h) restricts the number of layoffs in each period. (5i) provides a condition to check whether an innovative project has already been performed. (5j) satisfies the assumption by which each innovative project can be performed once. Moreover, we assume that a renewable energy source during the planning horizon can be integrated at most once. (6a) satisfies workforce balance in each period. (6b) satisfies inventory balance in each period. (6c) determines the number of stock-outs in line with sales and demand. In this constraint, we also consider the effect of implementing CSR projects on the demand. (6d) considers the productivity of different genders, training newly hired workers, and overtime working hours to find production capacity. We also assume that performing an innovative project in a period results in the decrease of production capacity in that period. However, it increases the production capacity in the next periods (see term $\sum_{k \in K}\left(c a_{t k}^{+} \times Y_{t k}^{A}-c a_{t k}^{-} \times Y_{t k}\right)$ ). (6e) restricts subcontracting capacity in each period. (6f) identifies the type of decision variables and non-negativity constraints. Note that one may assume that part-time employees are available in the aggregate plan. In this case, the number of male and female workers take non-integer values.

Theoretically, $F W_{t}, M W_{t}, F H_{t}, M H_{t}, F F_{t}, M F_{t}, P_{t}, I_{t}, S_{t}, S U_{t}$, and $S O_{t}$ are positive integer decision variables for all $t \in T$ (first two lines of (6f)). These variables constitute a number of decisions in the SAPP model. However, binary decision variables $\left(Y_{t k}, Y_{t k}^{A}, X_{t}^{R E}\right.$, and $C S R_{t j}$, where $t \in T, k \in K$, and $j \in J$ ) are directly related to strategic or more important tactical decisions. On the other hand, in order to reduce the complexity of the problem, we may assume that $F W_{t}$, $M W_{t}, F H_{t}, M H_{t}, F F_{t}, M F_{t}, P_{t}, I_{t}, S_{t}, S U_{t}$, and $S O_{t}$ are nonnegative variables $\left(\in \mathbb{R}^{+} \cup\{0\}\right)$ for all $t \in T$. Then, we round the solutions of these variables to the nearest integer values; the result will be highly reliable in terms of feasibility and optimality. In summary, the SAPP model involves four objective functions, binary, and continuous decision variables. The resulting model leads to a Quad-Objective MILP (QOMILP).

In our case study in the next section, the numerical scale of non-zero integer decision variables are sufficiently large and in the scale of hundred or thousand. Then, we can relax them to nonnegative real numbers without a significant change in the results.

\section{Case Study and Solution Approach}

In this paper, we illustrate the effectiveness of our SAPP model, solution approach, and analysis for supporting decision making in the presence of multiple criteria in a large manufacturer of household appliances in Turkey. This company exports products to many countries all around the globe. They have several facilities and production plants in Turkey, Europe, Far East, and Africa. They address sustainability as one of the core issues in their corporate agenda. For example, they have commissioned recycling facilities for old appliances. These types of activities have resulted in improvement of the image of the company to become one of the leaders in terms of green supply chain globally. In order to activate their SSCM strategies more, the stakeholders and managers of this company aim to prepare a master plan for the next 12 months that considers sustainability in their appliance manufacturing plants. 


\subsection{Customizing the SAPP Model Based on Case Study}

In this case study, we add some features to our general SAPP model presented in Section 3 to satisfy the specific requirements of the manufacturer. Hence, our SAPP model includes the following additional constraints for satisfying these concerns.

- Inventory level at the end of each month should not be smaller than a specific amount. Let $i n v_{t}^{\text {Lim }}$ be the lower bound for the inventory level at period $t$. Then, the SAPP model includes $I_{t} \geq i n v_{t}^{\text {Lim }}$ for $t=1, \ldots, 12$.

- The number of workers in manufacturing operations should be in a specific range. Let $w n^{L}$ and $w n^{U}$ be the lower and upper bound for the number of workers, respectively. Then, we add $w n^{L} \leq F W_{t}+M W_{t} \leq w n^{U}$ for $t=1, \ldots, 12$ to the set of constraints.

- There are no subcontracting activities due to quality assurance policies of the company.

We define three CSR and innovation projects $(|J|=|K|=3)$. The CSR projects include supporting female employees in workplaces, voluntary investments and support for healthcare systems and non-government organizations, and organizing campaigns to collect old products and replace them with new ones. These projects can be decided and advertised within a short period of time. So, they are applicable for APP problems.

In terms of innovative projects, we define them such that they provide more production capacity for the company one month after their implementation. Then, the company will be more responsive to the customers and during specific cultural, national, and religious holidays, more compensation can be extended to the workers. We list innovative projects as: setup of new production processes to improve efficiency, integrating new press machines in the system, and redesigning assembly lines with industry 4.0 and other efficient and innovative solutions. We focus on the levels of innovative projects which are implementable in one month and usable after that. The projects which require highly large amount of investments in long-terms of period are not in the scope of APP nor our problem.

For the rest of this paper, let $S$ and $x$ be the feasible region of the SAPP problem and decision variables for short, respectively. Moreover, $z_{p}(x)$ denotes the objective function value in pillar $p \in\{e c o, \ldots, c u l\}$ when decision variables are fixed to $x$. We also report the values for the parameters in Supplementary Material SM1.

\subsection{Normalizing the Objective Functions}

We aim to find appropriate values for the coefficients used in $z_{e n v}, z_{s o c}$, and $z_{c u l}$. Since the scale and unit of the terms given in (2a)-(2b), (3a)-(3d), and (4a)-(4b) are incompatible, normalizing these coefficients is crucial. We use normalization method proposed by Kim and de Weck (2005). For instance, we calculate normalized coefficient for coef $f_{\text {env } 1}$ in the following steps (Augusto et al., 2012):

- Maximize $\frac{\mathrm{Eq}(2 \mathrm{a})}{\text { coefenv1 }_{\text {en }}}$ subject to the feasible region $S$ and call the optimal objective function value $C^{\max }$.

- Minimize $\frac{\mathrm{Eq}(2 \mathrm{a})}{\text { coef }_{\text {env }}}$ subject to the feasible region $S$ and call the optimal objective function value $C^{\text {min }}$.

- Calculate $C o e f_{\text {env } 1}:=\frac{1}{C^{\max }-C^{\min }}$.

\subsection{Finding Non-Dominated Points}

We developed a QOMILP for the SAPP problem in Section 3. This problem consists of two maximization objective functions associated with the economic and cultural pillars and two minimization objective functions corresponding to the social and environmental pillars. Dealing with multiple objective functions challenges us to find ND points of the problem. A ND point or an efficient solution results in objective function values - in the objective space - that cannot be improved in all of objective functions simultaneously. Finding ND points is the most important task in multi-objective optimization. 
In terms of exact solution methods, there are a number of algorithms for multi-objective linear programs (MOLP) that are basically designed based on multi-criteria simplex method (Wiecek et al., 2016; Yu and Zeleny, 1975). When we study multi-objective integer linear programs (MOILP), the feasible region is not convex as of MOLPs, and hence, these problems are highly complex. There are a few papers for finding all ND points of MOILPs; for instance, Ehrgott (2006), Özlen and Azizoğlu (2009), Jorge (2009), Przybylski et al. (2010), Lokman and Köksalan (2013), Mavrotas and Florios (2013), and Ozlen et al. (2014) propose algorithms for solving MOILPs. A small number of studies exist in the literature with exact solution approach for finding the ND points of MOMILPs when the number of objective functions is greater than two (see Vincent et al. (2013), Belotti et al. (2013), Stidsen et al. (2014), Boland et al. (2015), Soylu and Yıldı (2016), and Fattahi and Turkay (2018) for solving bi-objective MILPs). We use the Generator of ND and Efficient Frontier (GoNDEF) method that ensures finding all or a large proportion of ND points for MOMILPs (Rasmi and Türkay, 2019). This method also enables generation of the ND points such that each of them is associated with a different binary solution. This feature for the generated solutions is not obtained if we use heuristic/metaheuristic methods for solving the QOMILP.

Next, we present the SAPP model in the following form to briefly explain the steps of GoNDEF. Note that all objective functions in (7) are shown in maximization form for simplicity.

$$
\begin{array}{cl}
\max & z_{1}\left(x_{C}, x_{B}\right)=z_{e c o}\left(x_{C}, x_{B}\right) \\
\max & z_{2}\left(x_{C}, x_{B}\right)=-z_{\text {env }}\left(x_{C}, x_{B}\right) \\
\max & z_{3}\left(x_{C}, x_{B}\right)=-z_{\text {soc }}\left(x_{C}, x_{B}\right) \\
\max & z_{4}\left(x_{C}, x_{B}\right)=z_{c u l}\left(x_{C}, x_{B}\right) \\
\text { s.t. } & A_{C}^{1} x_{C}+A_{B}^{1} x_{B} \leq b^{1}, A_{C}^{2} x_{C}+A_{B}^{2} x_{B}=b^{2}, \\
& x_{C} \in \mathbb{R}^{n_{C}}, x_{B} \in\{0,1\}^{n_{B}},
\end{array}
$$

where $x=\left(x_{C}, x_{B}\right), x_{C}$ is the vector of continuous decision variables in dimension $n_{C}$, and $x_{B}$ is the vector of binary decision variables in dimension $n_{B}$. Moreover, let matrices $A_{C}^{1}, A_{C}^{2}, A_{B}^{1}$, and $A_{B}^{2}$ specify the coefficients of $x_{C}$ and $x_{B}$ for defining the equality/inequality constraints. Righthand side values are also shown by $b^{1}$ and $b^{2}$. We also define point $z^{N a d i r}$ in the objective space such that $z_{p}^{\text {Nadir }}=\min \left\{z_{p}(x) \mid x \in S\right\}$ for $p=1, \ldots, 4$. Note that all points in the objective space dominate $z^{\text {Nadir }}$.

The SAPP model includes a number of continuous and binary decision variables (i.e. $n_{C}$ and $n_{B}$, respectively). Therefore, if a vector of continuous and binary values establish a feasible solution for the SAPP, then the vector of binary values is termed as a binary solution. Reminding that binary decision variables, $x_{B}$, correspond to strategic or more important tactical decisions, we use GoNDEF for finding the ND points such that each ND point is associated with a different strategic or binary solution. Moreover, these solutions are efficient and their image onto the objective space are not dominated by other points. Hence, we explore the trade-off of the solutions and provide supportive information for the decision making process.

Let an efficient binary solution be a binary solution such that there is at least one ND point corresponding to this binary solution. In other words, if we fix the binary variables to this solution, a vector of continuous values exists for the remaining LP which results in a ND point. For generating the ND points of the QOMILP, GoNDEF iteratively solves single objective MILPs (SOMILP) in the form of the problem given in (8). The objective function of this problem is the Manhattan distance of objective function values from $z^{\text {Nadir }}$ subject to the feasible regions updated iteratively.

$$
\begin{array}{ll}
\max & \sum_{p=1}^{4} \epsilon_{p} \\
\text { s.t. } & z_{p}\left(x_{C}, x_{B}\right)-\epsilon_{p} \geq z_{p}^{N a d i r}, \epsilon_{p} \geq 0, p=1, \ldots, 4, \\
& A_{C}^{1} x_{C}+A_{B}^{1} x_{B} \leq b^{1}, A_{C}^{2} x_{C}+A_{B}^{2} x_{B}=b^{2}, \\
& x_{C} \in \mathbb{R}^{n_{C}}, x_{B} \in\{0,1\}^{n_{B}} .
\end{array}
$$


At each iteration, a new potentially efficient binary solution is found; it is not definitely an efficient binary solution since we use some excluding constraints at each iteration and add them to (8). Note that no-good constraints and other excluding constraints are used to exclude binary solutions and the dominated cone of the ND points found, respectively. Therefore, repeated solutions are not obtained in solving the SOMILPs given in (8) at an iteration. In general, GoNDEF method consists of three main steps. Let EIS be the set of explored potentially efficient binary solutions. We set $E I S:=\emptyset$ at the beginning of the algorithm and indicate binary solutions by $x_{B}$ (see Rasmi and Türkay (2019) for detailed discussion).

Step1 Solve the SOMILP such that the binary solutions in the set of EIS are excluded. If $S O M I L P$ is infeasible, then terminate the algorithm. Otherwise, the solution is potentially a ND point such as $\bar{z}$ which corresponds to $\bar{x}_{B}$ and $\bar{x}_{B} \notin E I S$. Then, update EIS:= $E I S \cup\left\{\bar{x}_{B}\right\}$.

Step2 Check the dominance of $\bar{z}$. If $\bar{z}$ is ND, $\bar{x}_{B}$ is an efficient binary solution, and hence, exclude the dominated cone of $\bar{z}$ from the feasible region of the SOMILP and go to Step1. If $\bar{z}$ is dominated, check if $\bar{x}_{B}$ is an efficient binary solution (this issue is computed by using excluding constraints iteratively).

Step3 If $\bar{x}_{B}$ is an efficient binary solution, find a ND point corresponding to $\bar{x}_{B}$ and exclude its dominated cone from the feasible region of the SOMILP. Go to Step1.

We generate 591 ND points — corresponding to 591 different binary solutions — for the case study and analyze them in the following section to discuss the trade-off and the behavior of the objective functions. In order to denote the ND points in the following sections, let $z^{i}$ be the $i$ th ND point and assume that there exist $n$ ND points. Note that there is no priority among the objective functions as we use a multi-objective optimization method.

\subsection{Analysis of ND points and Trade-Offs}

We obtain a number of ND points. Let $z_{\text {max }}^{e c o}:=\left(z_{e c o}^{*}, z_{e n v}, z_{s o c}, z_{c u l}\right)$ be a ND point in the objective space such that $z_{\text {eco }}^{*}:=\max \left\{z_{\text {eco }}(x) \mid x \in S\right\}$. In other words, $z_{\text {eco }}^{*}$ is the optimal objective function value if we consider the total profit only. $z_{\max }^{e c o}$ is derived from a solution that does not result in a good performance in social, environmental, and cultural issues as the non-economic concerns. Then, we provide a framework to show that we can significantly improve sustainability in terms of the non-economic issues by allowing the economic performance to decrease slightly.

We report the performance of a ND point in four pillars by four numbers between 0 and 100 . 0 refers to the worst performance and 100 indicates the best performance. ND point $\hat{z}$ which is equal to $\left(\hat{z}_{\text {eco }}, \hat{z}_{\text {env }}, \hat{z}_{\text {soc }}, \hat{z}_{\text {cul }}\right)$ has the performance of 100 in the economic and cultural pillars if and only if $\hat{z}_{p}$ is equal to $\max \left\{z_{p}^{i} \mid i \in\{1, \ldots, n\}\right\}$ for $p \in\{e c o, c u l\}$. If $p \in\{e n v, \operatorname{soc}\}$, then $\hat{z}_{p}=\min \left\{z_{p}^{i} \mid i \in\right.$ $\{1, \ldots, n\}\}$ results in the performance of 100 . Note that we generate ND points such that $z_{\text {max }}^{\text {eco }}$, $z_{\text {min }}^{\text {env }}:=\left(z_{\text {eco }}, z_{\text {env }}^{*}, z_{\text {soc }}, z_{\text {cul }}\right), z_{\text {min }}^{\text {soc }}:=\left(z_{\text {eco }}, z_{\text {env }}, z_{\text {soc }}^{*}, z_{\text {cul }}\right)$, and $z_{\text {max }}^{c u l}:=\left(z_{\text {eco }}, z_{\text {env }}, z_{\text {soc }}, z_{\text {cul }}^{*}\right)$ exist in the set of generated ND points $\left(z_{\text {env }}^{*}:=\min \left\{z_{\text {env }}(x) \mid x \in S\right\}, z_{\text {soc }}^{*}:=\min \left\{z_{\text {soc }}(x) \mid x \in S\right\}\right.$, and $\left.z_{\text {cul }}^{*}:=\max \left\{z_{\text {cul }}(x) \mid x \in S\right\}\right)$. Moreover, we assign the performance of 0 to $\hat{z}_{p}$ if and only if it is equal to $\min \left\{z_{p}^{i} \mid i \in\{1, \ldots, n\}\right\}$ for $p \in\{e c o, c u l\}$ and $\max \left\{z_{p}^{i} \mid i \in\{1, \ldots, n\}\right\}$ for $p \in\{e n v$, soc $\}$. Note that if the maximization of an objective function is desirable, finding the worst objective function value or the performance of 0 is not computed by minimizing the objective function since we report the performance in each pillar regarding the ND points. We show the performance in pillar $p$ by $p f\left(z_{p}\right)$.

We also report $p f\left(z_{p}\right)$ for the other ND points based on the $z_{p}$ value in the interval of $\max \left\{z_{p}^{i} \mid i \in\{1, \ldots, n\}\right\}$ and $\min \left\{z_{p}^{i} \mid i \in\{1, \ldots, n\}\right\}$. For example, $p f\left(z_{\text {soc }}\right)=\frac{\max \left\{z_{\text {soc }}^{i} \mid i \in\{1, \ldots, n\}\right\}-z_{\text {soc }}}{\max \left\{z_{\text {soc }}^{i} \mid i \in\{1, \ldots, n\}\right\}-\min \left\{z_{\text {soc }}^{i} \mid i \in\{1, \ldots, n\}\right\}}$ 100 where minimization of $z_{s o c}(x)$ is desirable. For assessing the performance, we strongly believe that focusing on the ND points is more logical. There is no reason to come up with a solution dominated by other solutions. Then, we do not calculate the performance associated with an objective function value by its proportion to a range of objective function values corresponding to 
the dominated points. Therefore, for instance, $1 \%$ decrease in the economic performance is not equal to $1 \%$ decrease in the total profit; it is equal to $0.0781 \%$ decrease in the total profit.

Table 6 shows the correlation coefficients between every two vectors of the performances of the ND points. Six values exist in this table other than 1's. We note that three of them are negative and their absolute values are greater than the positive numbers. It shows that the performances of the object functions are conflicting rather than harmonious, and hence, using multi-criteria optimization approaches is important. Moreover, the most negative number is -0.676 which indicates the correlation coefficient between environmental and social pillar. This value also shows that the behavior of social and environmental objective functions is opposite. We will discuss the reasons in this section later.

Table 6: The correlation coefficient matrix of the pillar performances when the ND points are considered

\begin{tabular}{|c|cccc|}
\hline performance in & eco. & env. & soc. & cul. \\
\hline eco. & 1 & 0.426 & -0.485 & 0.214 \\
env. & & 1 & -0.676 & 0.396 \\
soc. & & & 1 & -0.654 \\
cul. & & & & 1 \\
\hline
\end{tabular}

We note that the performance in different issues are conflicting in many cases. Hence, obtaining the Ideal point as $(100,100,100,100)$ is impossible. Then, designing a supportive framework for decision makers is an important task in the SSCM. We select some of ND points out of the generated ND points to compare their performance in different pillars in Figures 2 and 3. We also show the performance of these ND points in Table 7.

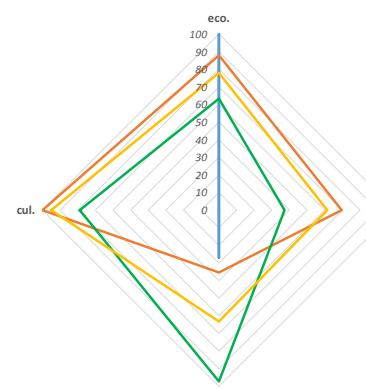

(a)

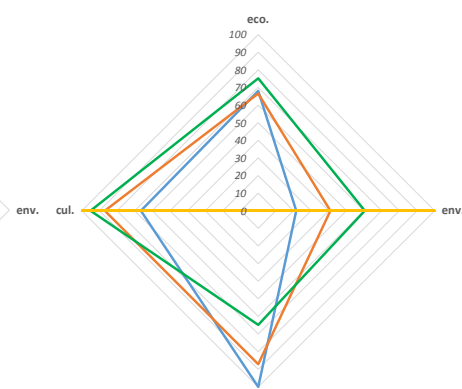

(b)

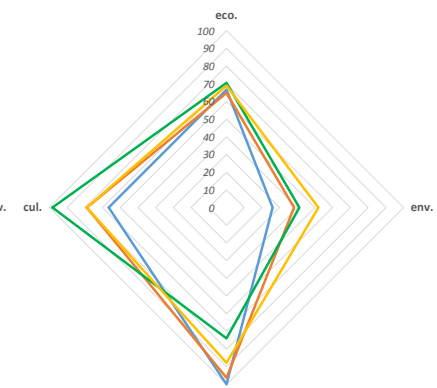

(c)

Figure 2: Exploring the performance trade-off between ND points

In Figure 2(a), we show the performance of $z_{\max }^{e c o}$ by blue color; $p f\left(z_{\text {eco }}\right)=100, p f\left(z_{s o c}\right)=27$, and the performance at this ND point is 0 for the environmental and cultural pillars. We show the performance of three other ND points in Figure 2(a) by red, yellow, and green colors. We denote that how fair decrements in the economic performance result in large and effective performance increase in non-economic issues. For example, if the manufacturer decides to allow the economic performance to decrease approximately $22 \%$ (such as the ND point associated with yellow color with the economic performance of 77.89), then the performance of environmental, social, and cultural issues can be improved by $61 \%, 36 \%$, and $95 \%$, respectively. The importance of this trade-off becomes more when we indicate that $22 \%$ decrease in the economic performance is equal to only $1.73 \%$ decrease in the total profit. This strategy is win-win since it significantly improves sustainability. This information is very supportive for decision makers to explore different strategies and find practical solutions based on their preferences.

In Figure 2(b), we show that focusing on environmental and cultural issues can result in a ND point (point associated with yellow color). However, we face a low performance in the social and economic pillars. Hence, similar to our discussion in Figure 2(a), we can find some ND points out of the generated ND points that fairly satisfy all pillars. For example, in the comparison between green and yellow solutions, there is a significant potentiality to capture a large performance in the economic and social pillars by small decrements in the other issues. 
Figure 2(c) shows four ND points with very close economic performances. Small changes in the economic performance lead to different performances in non-economic issues. Therefore, decision makers consider different factors, accept small changes for their goals, and make a decision.

\begin{tabular}{cccccc} 
& \multicolumn{5}{c}{ Table 7: The performance of the ND points shown in Figures 2 and 3} \\
\hline figure & $p f\left(z_{e c o}\right)$ & $p f\left(z_{e n v}\right)$ & $p f\left(z_{s o c}\right)$ & $p f\left(z_{\text {cul }}\right)$ & color \\
\hline $2(\mathrm{a})$ & 100.00 & 0.00 & 27.08 & 0.00 & blue \\
& 87.89 & 69.56 & 35.34 & 100.00 & red \\
& 77.89 & 61.43 & 63.16 & 94.98 & yellow \\
& 63.29 & 37.19 & 97.27 & 78.84 & green \\
\hline $2(\mathrm{~b})$ & 75.14 & 60.41 & 64.81 & 94.98 & green \\
& 68.02 & 21.59 & 100.00 & 66.52 & blue \\
& 66.49 & 40.92 & 87.11 & 86.91 & red \\
\hline $2(\mathrm{c})$ & 0.00 & 100.00 & 0.00 & 100.00 & yellow \\
& 70.55 & 41.14 & 73.99 & 98.27 & green \\
& 68.90 & 51.93 & 87.83 & 78.84 & yellow \\
& 66.65 & 26.01 & 100.00 & 66.52 & blue \\
& 64.74 & 38.14 & 96.32 & 78.84 & red \\
\hline 3 & 69.63 & 49.31 & 81.80 & 86.91 & blue \\
& 74.90 & 62.07 & 79.35 & 78.84 & red \\
& 77.89 & 61.43 & 63.16 & 94.98 & green \\
\hline
\end{tabular}

In Figure 3, we select three ND points based on three specific functions that logically come up with more balanced solutions. Let $p f\left(\bar{z}_{p}\right):=\frac{1}{n} \sum_{i=1}^{n} p f\left(z_{p}^{i}\right)$ for $p \in\{$ eco,,.,$c u l\}$. Then, the blue color shows the solution that minimizes the Euclidean distance between ND points and $\left(\bar{z}_{\text {eco }}, \bar{z}_{\text {env }}, \bar{z}_{\text {soc }}, \bar{z}_{\text {cul }}\right)$ and is calculated by $\min \left\{\sum_{p \in\{\text { eco, }, \ldots, c u l\}}\left(p f\left(z_{p}^{i}\right)-p f\left(\bar{z}_{p}\right)\right)^{2} \mid i \in\{1, \ldots, n\}\right\}$. Note that the minimum Manhattan distance - calculated by $\min \left\{\sum_{p \in\{\text { eco, }, \ldots, c u l\}}\left|p f\left(z_{p}^{i}\right)-p f\left(\bar{z}_{p}\right)\right| \mid i \in\right.$ $\{1, \ldots, n\}\}$ - is also provided by the ND point associated with blue color. Solution associated with red color minimizes the Euclidean distance between ND points and the Ideal point (calculated by $\left.\min \left\{\sum_{p \in\{e c o, \ldots, c u l\}}\left(p f\left(z_{p}^{i}\right)-100\right)^{2} \mid i \in\{1, \ldots, n\}\right\}\right)$ and the solution associated with green color minimizes the Manhattan distance between ND points and the Ideal point (calculated by $\left.\min \left\{\sum_{p \in\{\text { eco, }, \ldots, c u l\}}\left|p f\left(z_{p}^{i}\right)-100\right| \mid i \in\{1, \ldots, n\}\right\}\right)$. Moreover, let $p f\left(\bar{z}^{i}\right)=\frac{1}{4} \sum_{p \in\{\text { eco, }, \text {, cul }\}} p f\left(z_{p}^{i}\right)$ for $i \in\{1, \ldots, n\}$. Then, red solution also minimizes $\min \left\{\sum_{p \in\{e c o, \ldots, c u l\}}\left(p f\left(z_{p}^{i}\right)-p f\left(\bar{z}^{i}\right)\right)^{2} \mid i \in\right.$ $\{1, \ldots, n\}\}$ that results in a solution with the smallest variance in different pillars.

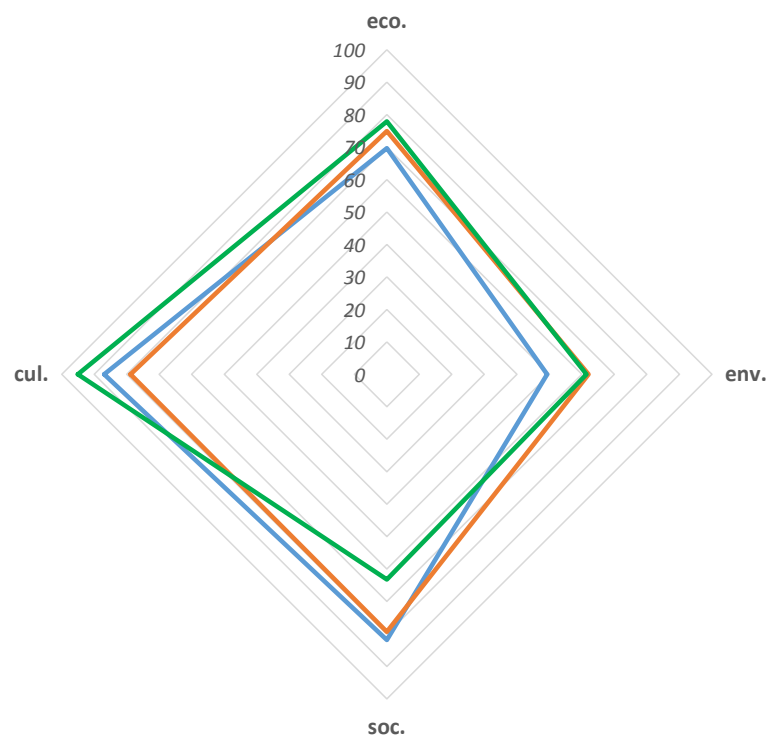

Figure 3: The performance of three ND points found using the specific functions suggested

We also analyze the strategic/tactical decisions that lead to the ND points. Let $Z_{60}$ be the set of ND points that are leading to more balanced performance in all pillars. The ND points in $Z_{60}$ 
have performances greater than 60 in all pillars $\left(\left|Z_{60}\right|=47\right)$. In Table 8 , we use the average value of different binary solutions corresponding to the ND points to analyze the impact of different strategic/tactical decisions. The second column shows the strategic/tactical decisions that result in $z_{\text {max }}^{e c o}$. The average values of the strategic/tactical decisions in the ND points in the set $Z_{60}$ and in the generated ND points are reported in the third and fourth columns.

Table 8: Summary of the strategic/tactical decisions correspond to the binary solutions of $z_{\text {max }}^{e c o}, Z_{60}$, and the entire ND points

\begin{tabular}{|c|c|c|c|}
\hline strategic/tactical decisions & $z_{\max }^{e c o}$ & $\begin{array}{l}\text { Avg. for NDs in } \\
Z_{60}\end{array}$ & $\begin{array}{l}\text { Avg. for the } \\
\text { generated NDs }\end{array}$ \\
\hline integration of a renewable energy source & 0 & 1 & 0.99 \\
\hline number of times that CSR project 1 is implemented & 0 & 3.73 & 9.08 \\
\hline number of times that CSR project 2 is implemented & 2 & 3.24 & 7.05 \\
\hline number of times that CSR project 3 is implemented & 0 & 10.37 & 10.99 \\
\hline performing innovative project 1 & 0 & 1 & 0.998 \\
\hline performing innovative project 2 & 1 & 1 & 1 \\
\hline performing innovative project 3 & 0 & 1 & 0.998 \\
\hline
\end{tabular}

Integrating a renewable energy source, implementing CSR projects, and performing innovative projects increase sustainability in a SAPP problem. These projects directly improve environmental, social, and cultural issues, respectively. Moreover, sometimes they indirectly affect other issues and improve them. Table 8 shows that the maximized total profit without concerning about sustainability is obtained by very few attention to the integration of a renewable energy source, CSR, and innovative projects. However, ND points in $Z_{60}$ are obtained by a significant attention to these projects.

In addition, although integration of a renewable energy source and performing innovative projects are vital for sustainability, implementing CSR projects in all periods may not be a sustainable win-win strategy resulting in balanced solutions. In the comparison of the third and fourth columns of Table 8, there is a significant difference in the number of CSR projects 1 and 2. Frequently implementation of CSR projects results in demand increase, more manufacturing and holding inventory activities, and decrease in the environmental performance. However, it improves the social and economic performance. Therefore, side-effects of a social-oriented activity must be considered.

Next, we briefly analyze the sensitivity of the economic objective function respect to changes in the parameters. We categorize basic parameters to two groups: $1-\alpha, o_{\text {Lim }}, \mathrm{fm}$, and $l_{\text {Lim }}$ which affect social-cultural objective function values directly, and $2-\xi_{g}$ and $\xi_{e}$ which impact the environmental objective function value directly.

In Figure 4(a,b), by the horizontal axis, we decrease the value of $\alpha$ and $\mathrm{fm}$, and increase the value of $o_{\text {Lim }}$ and $l_{\text {Lim }}$ simultaneously. Hence, the parameters change such that social-cultural issues are less respected. We observe that larger economic objective function values are obtainable by this approach (Figure 4(a)). Moreover, Figure 4(b) shows that, as we expect, the sum of the social and cultural objective function values increases or the social-cultural performance worsens.

We also examine the economic and environmental objective functions when $\xi_{g}$ and $\xi_{e}$ increase. We observe that if we set these parameters such that the environmental performance reduces, then larger economic objective function values are obtainable. However, after a level of environmental parameters, very small improvements in the economic objective function value is possible (Figure 4(c)). On the other hand, after that level, the environmental objective function apparently worsens.

\subsection{Managerial Insights}

The provided solutions in Figure 3 or the set $Z_{60}$ are useful since they give us more balanced solutions with performance which is not very far from the Ideal point. However, decision makers may prefer different solutions due to specific priorities or preferences. Generally, we point out a number of managerial insights regarding the SAPP problem and case study presented:

- We can approach an APP problem with sustainability considerations in five steps: 1- providing a multi/quad-objective mathematical model, 2- customizing the model based on the real problem, 3- normalizing the objective functions, 4- solving the multi-objective optimization problem to find ND points, and 5- finding the trade-off of different solutions and more balanced solutions and analyzing them. 
(a)

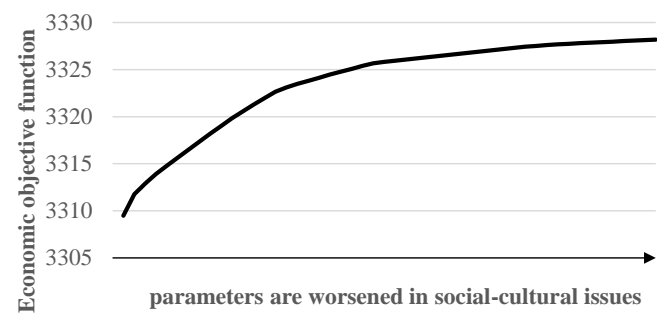

(c)

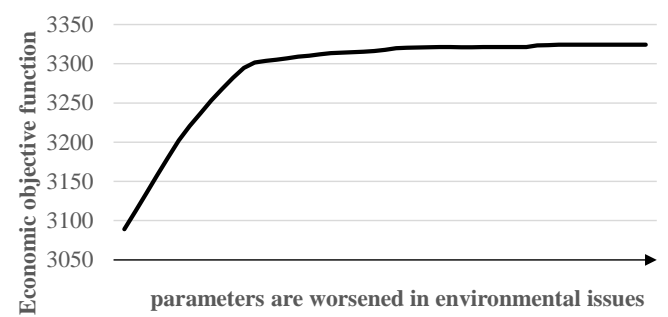

(b)

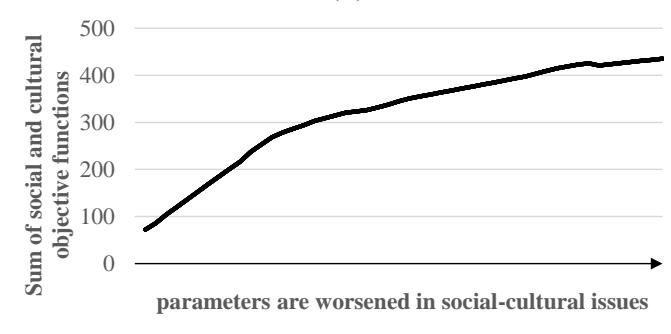

(d)

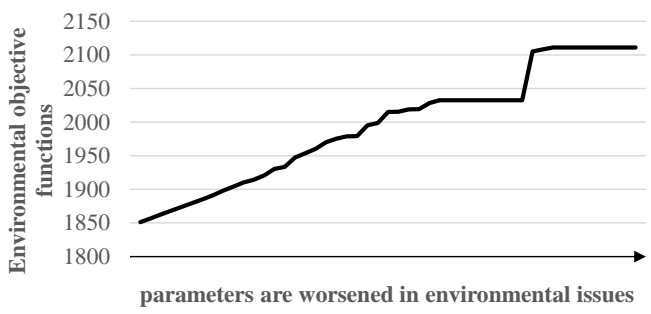

Figure 4: Sensitivity analysis when the parameters correspond social-cultural criteria worsen (a,b), and when the parameters associate the environmental pillar worsen $(\mathrm{c}, \mathrm{d})$

- Regarding the economic pillar, we consider sustainability-related costs such as carbon tax and energy cost that improve the economic objective function in terms of sustainability.

- Different indicators can be used in SAPP to address environmental, social, and cultural concerns. We present a number of these indicators in Table 2. Moreover, we show the way by which the indicators can be reflected in the objective functions and constraints of the SAPP model.

- As we generate $591 \mathrm{ND}$ points for the case study problem, a large number of ND points exist for real-world problems. In many cases, objective functions are conflicting, and hence, there are an exponentially large number of the ND points resulting in different performances and trade-offs. These solutions are compatible with different managerial approaches. We presented how some solutions assign a larger priority to some criteria.

- In many real-world problems, binary decision variables represent strategic or more important tactical decisions. For instance, making decision in multiple period of time for integrating renewable energy sources, performing innovative projects, and implementing CSR projects are represented by binary variables in the case study. There are a large number of ND points corresponding to different binary solutions. Hence, decision makers should note that there may exist many win-win strategies.

- In column three of Table 8, we observe that a balanced/win-win solution is not obtainable without sustainability-oriented projects. As seen in the case study problem, using energy from renewable sources and performing innovative/CSR projects are very important to have a sustainable supply chain. Decision makers should consider that the level of these projects may unbalance the results. Then, their side-effects are required to be accurately discussed. In general, conflicting objective functions cause debatable issues in sustainability.

- Some strategies increase the performance in social/cultural issues and demand, simultaneously. Decision makers should note that an increased demand may result in negative effects on the environment. Moreover, in column three of Table 8, we observe that the level of the implemented CSR projects is not equal to their maximum possible value (e.g. 12) for more balanced solutions. Thus, some CSR projects result in a lower performance in the environmental pillar for the company. However, they may lead to less energy consumption by the 
customers that improves environmental factors. For example, collecting old products and replacing them with new ones has a similar impact.

\section{Conclusions and Future Research Directions}

In this paper, we present a framework that supports multiple criteria decision making in the SAPP problems. We propose a QOMILP for these problems and address the economic, environmental, social, and cultural pillars simultaneously. Moreover, we enrich the consideration of each pillar by taking different practical sub-pillars into account. In this model, we put a significant emphasis on social issues that are infrequently addressed in the literature comparing with the environmental issues. In addition, we add cultural issues to the problem separated from the social pillar to comprehensively analyze four pillars of sustainability. We modify a solution method for QOMILPs to find a large number of ND points for our model that correspond to different strategies. Then, we show our analysis approach on a case study in the appliance manufacturing industry.

In the appliance manufacturing industry, maximizing the total profit without sustainability considerations results in a low performance in non-economic issues where the objective functions are conflicting. We show that how on-purpose small decrements in the total profit result in a significant performance increase for non-economic issues or sustainability. The manufacturer can reach high performances in the social, environmental, and cultural pillars by less than $2 \%$ decrease in the total profit. Moreover, in order to support decision making process, we use different functions to filter some unbalanced solutions out. The results are insightful for decision makers; however, they may modify the results based on their preference.

We show that using energy from renewable sources and implementing CSR/innovative projects improve sustainability and result in more balanced solutions. However, the projects that increase demand may lead to a lower performance in the environmental pillar. Therefore, decision makers require a comprehensive information about indirect effects of these projects.

We also show that there are a large number of strategic decisions that provide win-win solutions to the problem. Moreover, based on each strategic decision, there exist a large number of tactical and operational decisions which result in ND points. We describe that exploring the trade-off of the ND points constructively supports decision making process, and hence, decision makers reach balanced and practical solutions that address sustainability considerations. Furthermore, the proposed framework gives insights to decision makers for considering sustainability with their preferences and finding win-win paths to their goals.

We also see a potentiality for further studies in the future regarding SAPP. For example, an inclusive analysis is required to explore long-term effects of CSR projects on environmental issues. As we discuss in this paper, these projects may decrease the environmental performance of the manufacturer; however, from consumer point of view, total consumed energy is decreased, and the environmental performance is improved. Moreover, a study to discuss the impacts of CSR projects on the consumerism is important.

\section{References}

Anvari, S. and Turkay, M. (2017). The facility location problem from the perspective of triple bottom line accounting of sustainability. International Journal of Production Research, 55(21):62666287.

Arslan, M. C. (2011). Modeling and Analysis of Sustainable Supply Chain Systems. PhD thesis, Koç University.

Arslan, M. C. and Turkay, M. (2013). EOQ revisited with sustainability considerations. Foundations of Computing and Decision Sciences, 38(4):223-249.

Astara, O. H. (2014). Culture as the fourth pillar of sustainable development. Sustainable Development, Culture, Traditions, 1a:93 - 102.

Augusto, O. B., Bennis, F., and Caro, S. (2012). A new method for decision making in multiobjective optimization problems. Pesquisa Operacional, 32(2):331-369. 
Aviso, K. B., Tan, R. R., Culaba, A. B., and Cruz Jr, J. B. (2011). Fuzzy input-output model for optimizing eco-industrial supply chains under water footprint constraints. Journal of Cleaner Production, 19(2-3):187-196.

Azadnia, A. H., Saman, M. Z. M., and Wong, K. Y. (2015). Sustainable supplier selection and order lot-sizing: an integrated multi-objective decision-making process. International Journal of Production Research, 53(2):383-408.

Bask, A., Halme, M., Kallio, M., and Kuula, M. (2013). Consumer preferences for sustainability and their impact on supply chain management: The case of mobile phones. International Journal of Physical Distribution \& Logistics Management, 43(5/6):380-406.

Belotti, P., Soylu, B., and Wiecek, M. M. (2013). A branch-and-bound algorithm for biobjective mixed-integer programs. Optimization Online.

Benjaafar, S., Li, Y., and Daskin, M. (2013). Carbon footprint and the management of supply chains: Insights from simple models. IEEE transactions on automation science and engineering, 10(1):99-116.

Bhinge, R., Moser, R., Moser, E., Lanza, G., and Dornfeld, D. (2015). Sustainability optimization for global supply chain decision-making. Procedia CIRP, 26:323-328.

Bibowei, A. A. (2015). Workers knowledge of caues of workplace accidents in Bayelsa state. International Journal of Development Research, 5(06):4741-4757.

Boland, N., Charkhgard, H., and Savelsbergh, M. (2015). A criterion space search algorithm for biobjective mixed integer programming: The triangle splitting method. Technical report, Technical report, 2015. http://www. optimization-online. org/DB_HTML/2013/11/4107. html.

Brandenburg, M., Govindan, K., Sarkis, J., and Seuring, S. (2014). Quantitative models for sustainable supply chain management: Developments and directions. European Journal of Operational Research, 233(2):299-312.

CAAWS (2017). What is gender equity. Canadian Association for the Advanceent of Women and Sport and Physical Activity. Retrieved from: http://www.caaws.ca/gender-equity-101/ what-is-gender-equity/ Accessed 30.08.2018.

Chen, X., Benjaafar, S., and Elomri, A. (2013). The carbon-constrained eoq. Operations Research Letters, 41(2):172-179.

Chen, Z. and Andresen, S. (2014). A multiobjective optimization model of production-sourcing for sustainable supply chain with consideration of social, environmental, and economic factors. Mathematical Problems in Engineering, 2014.

Chopra, S. and Meindl, P. (2016). Supply Chain Management Strategy, Planning, and Operation. Prentice Hall, Upper Saddle River, New Jersey, $6^{\text {th }}$ edition.

Cities, U. and Governments, L. (2010). Culture: fourth pillar of sustainable development. United Cities and Local Governments (UCLG) Policy Statement.

Davizón, Y. A., Martínez-Olvera, C., Soto, R., Hinojosa, C., and Espino-Román, P. (2015). Optimal control approaches to the aggregate production planning problem. Sustainability, 7(12):16324-16339.

Dehghanian, F. and Mansour, S. (2009). Designing sustainable recovery network of end-of-life products using genetic algorithm. Resources, Conservation and Recycling, 53(10):559-570.

Dyllick, T. and Hockerts, K. (2002). Beyond the business case for corporate sustainability. Business strategy and the environment, 11(2):130-141. 
ECR (2017). Optimal shelf availability: Increasing shopper satisfaction at the moment of truth. Efficient Customer Response. Retrieved from: https://www.gs1.ch/docs/ default-source/prozesse-dokus/ecr-europe-osa---optimal-shelf-availability.pdf? sfvrsn=ddc66297_2 Accessed 30.08.2018.

Ehrgott, M. (2006). A discussion of scalarization techniques for multiple objective integer programming. Annals of Operations Research, 147(1):343-360.

Elkington, J. (1998). Partnerships from cannibals with forks: The triple bottom line of 21st-century business. Environmental Quality Management, 8(1):37-51.

Eskandarpour, M., Dejax, P., Miemczyk, J., and Péton, O. (2015). Sustainable supply chain network design: an optimization-oriented review. Omega, 54:11-32.

European Parliament (2016). Womens empowerment and its link to sustainable development. Directorate General for Internal Policies, Policy Department C: Citizens' Rights and Constitutional Affairs, Women's Rights \& Gender Equality. Retrieved from: http://www. europarl.europa.eu/RegData/etudes/IDAN/2016/556927/IPOL_ IDA (2016)556927_EN.pdf Accessed 30.08.2018.

Fareeduddin, M., Hassan, A., Syed, M., and Selim, S. (2015). The impact of carbon policies on closed-loop supply chain network design. Procedia CIRP, 26:335-340.

Fattahi, A. and Turkay, M. (2018). A one direction search method to find the exact nondominated frontier of biobjective mixed-binary linear programming problems. European Journal of Operational Research, 266(2):415-425.

Garbie, I. H. (2015). Sustainability optimization in manufacturing enterprises. Procedia CIRP, 26:504-509.

Hahn, G. J. and Brandenburg, M. (2017). A sustainable aggregate production planning model for the chemical process industry. Computers $\&$ Operations Research.

Handfield, R., Sroufe, R., and Walton, S. (2005). Integrating environmental management and supply chain strategies. Business strategy and the environment, 14(1):1-19.

Harraz, N. A. and Galal, N. M. (2011). Design of sustainable end-of-life vehicle recovery network in Egypt. Ain Shams Engineering Journal, 2(3-4):211-219.

Hawkes, J. (2001). The fourth pillar of sustainability: Culture's essential role in public planning. Common Ground.

Hopkins, M. S., Townend, A., Khayat, Z., Balagopal, B., Reeves, M., and Berns, M. (2009). The business of sustainability: what it means to managers now. MIT Sloan Management Review, $51(1): 20$.

Hovelaque, V. and Bironneau, L. (2015). The carbon-constrained eoq model with carbon emission dependent demand. International Journal of Production Economics, 164:285-291.

Hrymak, V. and Perezgonzalez, J. (2007). The costs and effects of workplace accidents: 20 case studies from ireland.

Jorge, J. M. (2009). An algorithm for optimizing a linear function over an integer efficient set. European Journal of Operational Research, 195(1):98-103.

Kim, I. Y. and de Weck, O. L. (2005). Adaptive weighted-sum method for bi-objective optimization: Pareto front generation. Structural and multidisciplinary optimization, 29(2):149-158.

Lackes, R. (2008). Coordinated production planning in supply chains. In 2008 IEEE International Conference on Industrial Engineering and Engineering Management, pages 1850-1854. IEEE.

Lee, D.-H., Dong, M., and Bian, W. (2010). The design of sustainable logistics network under uncertainty. International Journal of Production Economics, 128(1):159-166. 
Lokman, B. and Köksalan, M. (2013). Finding all nondominated points of multi-objective integer programs. Journal of Global Optimization, 57(2):347-365.

Lu, L. Y., Wu, C., and Kuo, T.-C. (2007). Environmental principles applicable to green supplier evaluation by using multi-objective decision analysis. International Journal of Production Research, 45(18-19):4317-4331.

Massaroni, E., Cozzolino, A., and Wankowicz, E. (2015). Sustainability in supply chain management - a literature review. Sinergie Italian Journal of Management, 33(98):331 - 355.

Mavrotas, G. and Florios, K. (2013). An improved version of the augmented $\varepsilon$-constraint method (augmecon2) for finding the exact pareto set in multi-objective integer programming problems. Applied Mathematics and Computation, 219(18):9652-9669.

May, G., Taisch, M., Bettoni, A., Maghazei, O., Matarazzo, A., and Stahl, B. (2015). A new human-centric factory model. Procedia CIRP, 26:103-108.

Melnyk, S. A., Davis, E. W., Spekman, R. E., and Sandor, J. (2010). Outcome-driven supply chains. MIT Sloan Management Review, 51(2):33.

Musavi, M. and Bozorgi-Amiri, A. (2017). A multi-objective sustainable hub location-scheduling problem for perishable food supply chain. Computers $\mathscr{E}$ Industrial Engineering, 113:766-778.

Nahmias, S. and Cheng, Y. (2009). Production and operations analysis, volume 6. McGraw-hill New York.

Özlen, M. and Azizoğlu, M. (2009). Multi-objective integer programming: a general approach for generating all non-dominated solutions. European Journal of Operational Research, 199(1):2535 .

Ozlen, M., Burton, B. A., and MacRae, C. A. (2014). Multi-objective integer programming: An improved recursive algorithm. Journal of Optimization Theory and Applications, 160(2):470-482.

Pérez-Fortes, M., Laínez-Aguirre, J. M., Arranz-Piera, P., Velo, E., and Puigjaner, L. (2012). Design of regional and sustainable bio-based networks for electricity generation using a multiobjective MILP approach. Energy, 44(1):79-95.

Pfeffer, J. (2010). Building sustainable organizations: The human factor. The Academy of Management Perspectives, 24(1):34-45.

Przybylski, A., Gandibleux, X., and Ehrgott, M. (2010). A two phase method for multi-objective integer programming and its application to the assignment problem with three objectives. Discrete Optimization, 7(3):149-165.

PwC (2013). Global Supply Chain Survey 2013: Next-generation supply chains efficient, fast and tailored. Retrieved from: https://www.pwc.com/gx/en/ consulting-services/supply-chain/global-supply-chain-survey/assets/ global-supply-chain-survey-2013.pdf Accessed 30.08.2018.

Rasmi, S. A. B. and Türkay, M. (2019). Gondef: an exact method to generate all nondominated points of multi-objective mixed-integer linear programs. Optimization and Engineering, 20(1):89-117.

Russell, R. S. and Taylor-Iii, B. W. (2008). Operations management along the supply chain. John Wiley \& Sons.

Salmona, M. O. A., Selam, A. A., and Vayvay, O. (2010). Sustainable supply chain management: A literature review. In International Conference on Value Chain Sustainability (ICOVACS 2010).

Santibañez-Aguilar, J. E., González-Campos, J. B., Ponce-Ortega, J. M., Serna-González, M., and El-Halwagi, M. M. (2014). Optimal planning and site selection for distributed multiproduct biorefineries involving economic, environmental and social objectives. Journal of cleaner production, 65:270-294. 
Sarkis, J., Helms, M. M., and Hervani, A. A. (2010). Reverse logistics and social sustainability. Corporate Social Responsibility and Environmental Management, 17(6):337-354.

Schenker, S., Steingrímsson, J. G., Borndörfer, R., and Seliger, G. (2015). Modelling of bicycle manufacturing via multi-criteria mixed integer programming. Procedia CIRP, 26:276-280.

Schroeder, R. G. and Larson, P. D. (1986). A reformulation of the aggregate planning problem. Journal of Operations Management, 6(3-4):245-256.

Soini, K., Battaglini, E., Birkeland, I., Duxbury, N., Fairclough, G., Horlings, L., and Dessein, J. (2015). Culture in, for and as sustainable development: Conclusions from the COST Action IS1007 investigating cultural sustainability. University of Jyväskylä.

Soleimani, H., Govindan, K., Saghafi, H., and Jafari, H. (2017). Fuzzy multi-objective sustainable and green closed-loop supply chain network design. Computers $\mathcal{E}$ Industrial Engineering, 109:191-203.

Soylu, B. and Yıldız, G. B. (2016). An exact algorithm for biobjective mixed integer linear programming problems. Computers \& Operations Research, 72:204-213.

Stevenson, W. J., Hojati, M., and Cao, J. (2007). Operations management, volume 8. McGrawHill/Irwin Boston.

Stidsen, T., Andersen, K. A., and Dammann, B. (2014). A branch and bound algorithm for a class of biobjective mixed integer programs. Management Science, 60(4):1009-1032.

Towers, N. and Ashford, R. (2001). The supply chain management of production planning and sustainable customer relationships. Management research news, 24(12):1-6.

Trudel, R. and Cotte, J. (2009). Does it pay to be good? MIT Sloan Management Review, 50(2):61.

Tsoulfas, G. T. and Pappis, C. P. (2008). A model for supply chains environmental performance analysis and decision making. Journal of cleaner production, 16(15):1647-1657.

Türkay, M. (2008). Environmentally conscious supply chain management. Process systems engineering, pages 87-105.

Türkay, M., Saraçoğlu, Ö., and Arslan, M. C. (2016). Sustainability in supply chain management: Aggregate planning from sustainability perspective. PloS one, 11(1):e0147502.

Validi, S., Bhattacharya, A., and Byrne, P. (2014). A case analysis of a sustainable food supply chain distribution system - a multi-objective approach. International Journal of Production Economics, 152:71-87.

Varsei, M. (2016). Sustainable supply chain management: A literature review. In Australia-Middle East Conference on Business and Social Sciences 2016, Dubai.

Vincent, T., Seipp, F., Ruzika, S., Przybylski, A., and Gandibleux, X. (2013). Multiple objective branch and bound for mixed 0-1 linear programming: Corrections and improvements for the biobjective case. Computers \& Operations Research, 40(1):498-509.

Wagstaff, A. S. and Lie, J.-A. S. (2011). Shift and night work and long working hours-a systematic review of safety implications. Scandinavian journal of work, environment $\& 3$ health, pages 173185.

Wiecek, M. M., Ehrgott, M., and Engau, A. (2016). Continuous Multiobjective Programming, pages 739-815. Springer New York, New York, NY.

Yamada, T., Yoshizaki, Y., Itsubo, N., and Inoue, M. (2015). Low-carbon and economic supplier selection using life cycle inventory database by asian international input-output tables. Procedia CIRP, 26:317-322. 
Yencken, D. and Wilkinson, D. (2001). Resetting the compass: Australia's journey towards sustainability. CSIRO publishing.

Yu, P. and Zeleny, M. (1975). The set of all nondominated solutions in linear cases and a multicriteria simplex method. Journal of Mathematical Analysis and Applications, 49(2):430-468.

Zhou, Z., Cheng, S., and Hua, B. (2000). Supply chain optimization of continuous process industries with sustainability considerations. Computers 83 Chemical Engineering, 24(2-7):1151-1158.

Zimara, V. and Eidam, S. (2015). The benefits of social sustainability reporting for companies and stakeholders-evidence from the German chemical industry. Journal of Business Chemistry, $12(3)$. 


\section{Supplementary Material:}

A Multi-Criteria Decision Analysis to Include Environmental, Social, and Cultural Issues in the Sustainable Aggregate Production Plans

SM1: Parameters of the Case Study

Table 1: The values for parameters in the case study ( $\$$ refers to the currency which is Turkish lira in the case study)

\begin{tabular}{|c|c|c|c|c|c|c|c|c|c|c|c|c|c|}
\hline$t$ & month & 1 & 2 & 3 & 4 & 5 & 6 & 7 & 8 & 9 & 10 & 11 & 12 \\
\hline$d_{t}$ & item & 217823 & 217316 & 260104 & 256002 & 317527 & 329603 & 312316 & 383955 & 310242 & 267525 & 245584 & 195383 \\
\hline$h$ & hour/day & 8 & & & & & & & & & & & \\
\hline$n_{t}$ & day & 20 & 20 & 27 & 25 & 24 & 20 & 18 & 25 & 23 & 25 & 26 & 20 \\
\hline$p_{M}$ & item $/($ worker $\times$ day $)$ & 4.8 & & & & & & & & & & & \\
\hline$M W_{0}$ & worker & 1674 & & & & & & & & & & & \\
\hline$F W_{0}$ & worker & 226 & & & & & & & & & & & \\
\hline$I_{0}$ & item & 84757 & & & & & & & & & & & \\
\hline$s p$ & $\$ /$ item & 1463 & & & & & & & & & & & \\
\hline${ }^{c_{L}}$ & $\$ /($ worker $\times$ hour $)$ & 19.06 & & & & & & & & & & & \\
\hline${ }^{c}{ }_{H}$ & $\$ /$ worker & 1000 & & & & & & & & & & & \\
\hline${ }^{c} F$ & $\$ /$ worker & 3500 & & & & & & & & & & & \\
\hline$c_{M}$ & $\$ /$ item & 732 & & & & & & & & & & & \\
\hline$c_{O}$ & $\$ /($ worker $\times$ hour $)$ & 28.6 & & & & & & & & & & & \\
\hline$c_{I}$ & $\$ /($ item $\times$ period $)$ & 9.86 & & & & & & & & & & & \\
\hline$c_{S O}$ & $\$ /$ item & 950 & & & & & & & & & & & \\
\hline${ }^{c} C T$ & $\$ /$ tonne & 150 & & & & & & & & & & & \\
\hline$c_{E}$ & $\$ / \mathrm{kWh}$ & 410 & & & & & & & & & & & \\
\hline$c_{t}^{R E}$ & $\$$ & 3000000 & 2750000 & 2500000 & 2250000 & 2000000 & 1750000 & 1500000 & 1250000 & 1000000 & 750000 & 500000 & 250000 \\
\hline$c_{t 1}^{C S R}$ & $\$$ & 3750000 & 3750000 & 3750000 & 3750000 & 3750000 & 3750000 & 4250000 & 4250000 & 4250000 & 4250000 & 4250000 & 4250000 \\
\hline$c_{t 2}^{C S R}$ & $\$$ & 3000000 & 3000000 & 3000000 & 3000000 & 4000000 & 4000000 & 4000000 & 5000000 & 5000000 & 5000000 & 5000000 & 5000000 \\
\hline$c_{t 3}^{C S R}$ & $\$$ & 3500000 & 3500000 & 3500000 & 3500000 & 3500000 & 3500000 & 3500000 & 3500000 & 3500000 & 3500000 & 3500000 & 3500000 \\
\hline$c_{t 1}^{I N}$ & $\$$ & 9000000 & 8250000 & 7500000 & 6750000 & 6000000 & 5250000 & 4500000 & 3750000 & 3000000 & 2250000 & 1500000 & 750000 \\
\hline$c_{t 2}^{I N}$ & $\$$ & 6000000 & 5500000 & 5000000 & 4500000 & 4000000 & 3500000 & 3000000 & 2500000 & 2000000 & 1500000 & 1000000 & 500000 \\
\hline$c_{t 3}^{I N}$ & $\$$ & 12000000 & 11000000 & 10000000 & 9000000 & 8000000 & 7000000 & 6000000 & 5000000 & 4000000 & 3000000 & 2000000 & 1000000 \\
\hline$w n^{L}$ & worker & 1650 & & & & & & & & & & & \\
\hline$w n U$ & worker & 2750 & & & & & & & & & & & \\
\hline$g_{I}$ & tonne $/($ item $\times$ period $)$ & 0.0048 & & & & & & & & & & & \\
\hline$g_{P}$ & tonne/item & 0.0379 & & & & & & & & & & & \\
\hline$e_{I}$ & $\mathrm{kWh} /($ item $\times$ period $)$ & 0.0057 & & & & & & & & & & & \\
\hline$e_{P}$ & $\mathrm{kWh} /$ item & 0.1346 & & & & & & & & & & & \\
\hline$e_{t}^{R E}$ & $\mathrm{kWh}$ & 1800 & 1650 & 1500 & 1350 & 1200 & 1050 & 900 & 750 & 600 & 450 & 300 & 150 \\
\hline$\xi_{g}$ & tonne & 150000 & & & & & & & & & & & \\
\hline$\xi_{e}$ & $\mathrm{kWh}$ & 500000 & & & & & & & & & & & \\
\hline$\alpha$ & $\%$ & 0.975 & & & & & & & & & & & \\
\hline${ }^{l}{ }_{\text {Lim }}$ & $\%$ & 0.1 & & & & & & & & & & & \\
\hline$o_{\text {Lim }}$ & hour/period & 20 & & & & & & & & & & & \\
\hline$f m$ & $\%$ & 0.3 & & & & & & & & & & & \\
\hline$p h$ & $\%$ & 0.6 & & & & & & & & & & & \\
\hline$p f$ & $\%$ & 0.97 & & & & & & & & & & & \\
\hline$d_{t 1}^{+}$ & $\%$ & 0.014 & 0.014 & 0.014 & 0.014 & 0.014 & 0.014 & 0.017 & 0.017 & 0.017 & 0.017 & 0.017 & 0.017 \\
\hline$d_{t 2}^{+}$ & $\%$ & 0.02 & 0.02 & 0.02 & 0.02 & 0.02 & 0.02 & 0.02 & 0.02 & 0.02 & 0.02 & 0.02 & 0.02 \\
\hline$d_{t 3}^{+}$ & $\%$ & 0.021 & 0.021 & 0.018 & 0.018 & 0.015 & 0.014 & 0.015 & 0.013 & 0.015 & 0.017 & 0.019 & 0.024 \\
\hline$c a-\overline{t 1}$ & item & 13000 & 13000 & 11500 & 12250 & 16000 & 20000 & 21000 & 18500 & 16000 & 13000 & 11250 & 11250 \\
\hline$c a_{t 2}^{-}$ & item & 10000 & 10000 & 9250 & 9750 & 12750 & 16000 & 16750 & 14750 & 13000 & 10250 & 9000 & 9000 \\
\hline$c a_{t 3}^{-}$ & item & 16000 & 16000 & 14500 & 15500 & 21500 & 28000 & 29500 & 25500 & 22000 & 16500 & 14000 & 14000 \\
\hline$c a_{t 1}^{+}$ & item & 12000 & 12000 & 12000 & 12000 & 12000 & 12000 & 12000 & 12000 & 12000 & 12000 & 12000 & 12000 \\
\hline$c a_{t 2}^{+}$ & item & 7000 & 7000 & 7000 & 7000 & 7000 & 7000 & 7000 & 7000 & 7000 & 7000 & 7000 & 7000 \\
\hline$c a_{t 3}^{+}$ & item & 15000 & 15800 & 19000 & 18500 & 23000 & 24000 & 22500 & 28000 & 22500 & 19500 & 18000 & 13500 \\
\hline$g_{t 1}^{\overline{-}}$ & tonne & 1518 & 1380 & 1242 & 1104 & 966 & 828 & 690 & 552 & 414 & 276 & 138 & 0 \\
\hline$g_{t 2}^{-}$ & tonne & 731 & 665 & 600 & 532 & 465 & 399 & 332 & 266 & 200 & 133 & 66 & 0 \\
\hline$g_{t 3}^{-}$ & tonne & 3028 & 2815 & 2558 & 2308 & 1998 & 1674 & 1370 & 992 & 690 & 425 & 182 & 0 \\
\hline$e_{t 1}^{-}$ & $\mathrm{kWh}$ & 4290 & 3900 & 3510 & 3120 & 2730 & 2340 & 1950 & 1560 & 1170 & 780 & 390 & 0 \\
\hline$e_{t 2}^{-}$ & $\mathrm{kWh}$ & 2310 & 2100 & 1890 & 1680 & 1470 & 1260 & 1050 & 840 & 630 & 420 & 210 & 0 \\
\hline$e_{t 3}^{-}$ & $\mathrm{kWh}$ & 8411 & 7818 & 7106 & 6412 & 5550 & 4650 & 3806 & 2756 & 1912 & 1181 & 506 & 0 \\
\hline$i n v_{t}^{L i m}$ & item & 72439 & 86701 & 85334 & 105842 & 109868 & 104105 & 127985 & 103414 & 89175 & 81861 & 65128 & 65000 \\
\hline${ }^{c s r}{ }_{\text {Lim }}$ & \# of projects & 1 & & & & & & & & & & & \\
\hline${ }^{i n}$ Lim & \# of projects & 1 & & & & & & & & & & & \\
\hline
\end{tabular}

